\title{
Salidroside prevents skin carcinogenesis induced by DMBA/TPA in a mouse model through suppression of inflammation and promotion of apoptosis
}

\author{
YING-HUI KONG and SU-PING XU \\ Department of Dermatology, Huai'an First People's Hospital, Nanjing Medical University, Huai'an, Jiangsu 223300, P.R. China
}

Received September 25, 2017; Accepted March 20, 2018

DOI: $10.3892 /$ or.2018.6381

\begin{abstract}
Salidroside (SR) is a main component of Rhodiola rosea $\mathrm{L}$. and exhibits a variety of pharmacologic properties. The present study was carried out to explore the potential effect of SR against skin cancer induced by 7,12-dimethylbenz( $a$ ) anthracene (DMBA) and 12-O-tetradecanoylphorbol13-acetate (TPA) in female Institute for Cancer Research (ICR) mice and to reveal the underlying molecular targets regulated by SR. The mice were randomly divided into 4 groups: control, DMBA/TPA, DMBA/TPA+SR (20 mg/kg) and DMBA/ TPA+SR (40 mg/kg). SR was administered to mice five times a week after DMBA treatments. In our study, we found that SR dose-dependently ameliorated skin cancer incidence and the multiplicity in the animal models by reducing the release of inflammation-related cytokines, including tumor necrosis factor $\alpha(\mathrm{TNF}-\alpha)$, interleukin-1 $\beta$ (IL-1 $\beta)$, interleukin-18 (IL-18), interleukin-6 (IL-6), cyclooxygenase 2 (COX2) and transforming growth factor $\beta-1$ (TGF- $\beta 1$ ). Suppression of the nuclear factor (NF) $-\kappa B$ signaling pathway by SR was effective to prevent skin carcinogenesis. Furthermore, TUNEL analysis indicated that compared to the DMBA/TPA group, enhanced apoptosis was observed in the DMBA/TPA+SR group. In addition, p53 expression levels were increased by $\mathrm{SR}$ in the DMBA/TPA-induced mice. Therefore, SR was effective for inducing apoptosis during skin cancer progression triggered by DMBA/TPA. Consistently, p21, p53 upregulated modulator of apoptosis (PUMA), Bax and caspase-3 were highly induced by SR to enhance the apoptotic response for preventing skin cancer. Moreover, in vitro, we found that SR dramatically reduced the inflammatory response, while enhancing the aoptotic response by blocking NF- $\kappa \mathrm{B}$ and activating caspase-3 pathways, respectively. In addition, flow cytometric analysis
\end{abstract}

Correspondence to: Dr Ying-Hui Kong, Department of Dermatology, Huai'an First People's Hospital, Nanjing Medical University, 6 Beijing Road West, Huai'an, Jiangsu 223300, P.R. China

E-mail: kongyinghuinmuu@foxmail.com; zou@qq.com

Key words: salidroside, skin cancer, inflammation, $\mathrm{NF}-\kappa \mathrm{B}$, apoptosis further confirmed the induction of apoptosis by SR in DMBAtreated cells in vitro. Taken together, the in vivo and in vitro studies illustrated that SR might be a promising compound to reduce skin cancer risk.

\section{Introduction}

Non-melanoma skin cancer (NMSC) includes squamous cell carcinoma (SCC) and basal cell carcinoma (BCC) $(1,2)$. BCC represents $\sim 80 \%$, and SCC accounts for $\sim 20 \%$ of all diagnosed NMSC cases worldwide (3). According to previous reports, SCC has a higher prevalence in comparison to BCC (4). Apart from ultraviolet radiation (UVR), other common risk factors of NMSC include occupational and environmental exposures to polycyclic aromatic hydrocarbons, arsenic, and ionizing radiation (5). Polycyclic aromatic hydrocarbons originate during the incomplete combustion of organic materials, including wood, petroleum and coal, and are well known for their toxic abilities apart from being carcinogenic and mutagenic in nature (6,7). 7,12-Dimethylbenz( $a$ )anthracene (DMBA) is the most common polycyclic aromatic hydrocarbon used as an initiating agent in chemically triggered skin cancer models, and 12- $O$-tetradecanoylphorbol-13-acetate (TPA), as a tumor promoter inducing two-stage skin cancer model, has been illustrated to closely mimic human SCC (8-10). In general, skin carcinogenesis is known as a multistep procedure, which consists of initiation, acceleration, development and progression (11). Identification of effective chemoprevention agents seems to be one of the most feasible strategies to reverse or impede carcinogenesis $(12,13)$.

Salidroside (SR), 2-(4-hydroxyphenyl)ethyl $\beta$-D-glucopyranoside, is a phenylpropanoid glycoside, which is extracted from the root of Rhodiola rosea $\mathrm{L}$. and has been applied as a medicinal herb to protect erythrocytes against oxidative stress and enhance resistance to fatigue $(14,15)$. In addition, SR was found to inhibit the inflammatory response by regulating the nuclear factor (NF)- $\mathrm{B}$ pathway, ameliorating gastric damage (16). Furthermore, SR was reported to modulate the apoptotic response via altering the expression levels of apoptosis-related signals in various diseases $(17,18)$. In addition, the protective effects of SR are considered to be related to its anti-inflammatory properties in different diseases $(15,19)$. 
However, to date, the innate mechanism of skin cyto-protection is consistently diminished or is not adequate to ameliorate cellular transformation caused by radiation and various chemical carcinogens (20). Considering the application of $\mathrm{SR}$ in various diseases, it may be an effective candidate with which to prevent skin carcinogenesis.

Inflammation is a key molecular mechanism which induces disorders in organisms, including skin disease $(21,22)$. According to previous studies, a variety of pro-inflammatory cytokines, such as interleukins (ILs), and tumor necrosis factor (TNF), and the anti-inflammatory factor TGF- $\beta 1$, are overexpressed in the skin under different conditions (23). $\mathrm{NF}-\kappa \mathrm{B}$ plays an essential role in different pathologies via regulation of chemokines, cytokines as well as cell adhesion molecules $(24,26)$. Liberation from I $\kappa$ B promotes $N F-\kappa B$ to translocate into the nucleus. Then, it induces gene transcription through combination with $\mathrm{NF}-\kappa \mathrm{B}$ responsive gene promoter (26). Furthermore, apoptosis is the most common, gene-directed form of programmed cell death, contributing to different physiologic and pathologic processes (27). Apoptosis has been characterized as an important molecular mechanism and various drugs have been explored for preventing apoptosis in different types of tumors $(28,29)$. As previously reported, apoptosis is involved in skin cancer development, which is dependent on the expression of anti-apoptotic and pro-apoptotic signals $(30,31)$. Based on the effects of SR on inflammation and apoptosis, here, in our study, we attempted to assess the preventive role of SR in DMBA/TPA-induced two-stage skin cancer. Parameters of body weight, tumor incidence, tumor size and the number of lesions were measured to calculate the chemo-preventive value of SR. The inflammatory and apoptotic response were also investigated to explain the molecular mechanisms of SR during the regulation of skin carcinogenesis.

\section{Materials and methods}

Animals and treatments. Eighy female Institute of Cancer Research (ICR) mice, 6-7 weeks of age, were purchased from the Shanghai Experimental Animal Center (Shanghai, China) and kept in climate-controlled quarters with a 12-h light and dark cycle with food and water in cages under germ-free conditions. All experimental procedures were carried out following the Guide for the Care and Use of Laboratory Animals of Huai'an First People's Hospital, Nanjing Medical University (Nanjing, China) and before the animal experiments were performed, the procedures were approved by the Research Ethics Committee of Huai'an First People's Hospital, Nanjing Medical University (Nanjing, China).

ICR mice were randomly divided into four groups, 20 animals per group. The experimental design of the in vivo study is exhibited in Fig. 1A. All mice were shaved ahead of our study. In brief, the groups receiving DMBA/TPA, and DMBA/TPA+SR were first administered $60 \mu \mathrm{g}$ DMBA dissolved in $0.2 \mathrm{ml}$ to the naked backs. DMBA was administered to mice for two weeks, from week 1 to week 3 . The first two weeks after skin tumor initiation with DMBA, animals in the DMBA/TPA and DMBA/TPA+SR groups were further exposed to $4 \mu \mathrm{g}$ TPA twice a week for a total of 20 weeks ranging from week 3 to week 23 . In addition, the mice treated with SR (20 and $40 \mathrm{mg} / \mathrm{kg}$ ) were topically treated $30 \mathrm{~min}$ before each DMBA/TPA treatment five times a week until the sacrifice of the animals at week 22 (32-35). DMBA and TPA were purchased from Sigma-Aldrich (St. Louis, MO, USA). SR (>98\% purity, molecular formula: $\mathrm{C}_{14} \mathrm{H}_{20} \mathrm{O}_{7}$, CAS 10338-51-9) was purchased from Shanghai Ronghe Medicine Science and Technology Development Co, Ltd. (Shanghai, China). Sizes of the skin tumors $>1 \mathrm{~mm}$ in diameter were measured every week using calipers. The dorsal skin of mice derived from different experiments was excised. After the fat was removed from the dorsal skin on ice, the skin tissue samples were placed in liquid nitrogen immediately for further research. The eye blood was collected for pro-inflammatory cytokine determination.

Cells and culture. Normal human epidermal keratinocytes, $\mathrm{HaCaT}$, were purchased from Combioer Biosciences Co., Ltd. (Nanjing, China). Human hypertrophic scar fibroblasts (HSFs) were purchased from Bioleaf Corp. (Shanghai, China). Human normal liver cell line L02 was obtained from the Cell Bank of the Type Culture Collection of the Chinese Academy of Science (Shanghai, China). All cells were cultured and maintained in Dulbecco's modified Eagle's medium (DMEM) containing 10\% fetal bovine serum (FBS) (Gibco; Thermo Fisher Scientific, Inc., Waltham, MA, USA) and 1\% penicillin/ streptomycin (Gibco; Thermo Fisher Scientific, Inc.) in a humidified $5 \% \mathrm{CO}_{2}$ atmosphere at $37^{\circ} \mathrm{C}$. SR used for the treatment of skin cancer was dissolved in DMSO (KeyGen Biotech Co., Ltd., Nanjing, China) and stored at $-20^{\circ} \mathrm{C}$, and then it was diluted in DMEM at the indicated concentrations for experimental treatment. The final DMSO concentration was no more than $0.1 \%(\mathrm{v} / \mathrm{v})$ in each treatment.

MTT assay. To calculate the growth inhibitory role of SR in different cell lines, $\sim 1 \times 10^{3}$ cells/well were planted in 96-well plates (Corning Inc., Corning, NY, USA) with complete growth medium. On the following day, the cells were treated with different concentrations of SR ranging from 0 to $160 \mu \mathrm{M}$ and incubated at $37^{\circ} \mathrm{C}$ for $24 \mathrm{~h}$. Then, the cell viability was determined by 3-(4,5-dimethylthiazol-2-yl)-2,5-diphenyl$2 \mathrm{H}$-tetrazolium bromide (MTT) assay at $570 \mathrm{~nm}$.

Flow cytometric analysis. The Annexin V-FITC/propidium iodide (PI) apoptosis detection kit was purchased from KeyGen Biotech Co., Ltd., to measure the apoptotic cell levels. All cells after the different treatments as described were harvested and washed with ice-cold PBS for twice, then incubated in a darkroom with Annexin V-FITC and PI for $15 \mathrm{~min}$. Subsequently, the cells were analyzed by flow cytometry (BD Biosciences, San Jose, CA, USA). The percentage of cells undergoing apoptosis was quantified.

ELISA methods. The eye blood was subjected to centrifugation at $12,000 \mathrm{x}$ g for $10 \mathrm{~min}$ to carefully collect the supernatant. Then, TNF- $\alpha$, IL-1 $\beta$, IL-18, IL-6, COX2 and TGF- $\beta 1$ levels in serum were determined using the Mouse TNF- $\alpha$ Quantikine ELISA kit (R\&D Systems, Inc., Minneapolis, MN, USA), Mouse IL-1 $\beta$ ELISA kit (IL-1 $\beta$ ) (Abcam, Cambridge, UK), Mouse IL-18 ELISA (R\&D Systems, Inc.), Mouse IL-6 Quantikine ELISA kit (R\&D Systems, Inc.), Mouse COX2 
ELISA kit (Abcam) and Mouse TGF- $\beta 1$ ELISA kit (Abcam) following the manufacturer's instructions.

Histochemical analysis. Fixed skin and tumor tissues obtained from mice were embedded in paraffin blocks and $3-\mu \mathrm{m}$ thick sections were cut. Skin and tumor sections were then deparaffinized and stained with hematoxylin and eosin (H\&E) staining. The thickness of the skin epidermis was measured using Magnus Analytics Magnuspro software. Epidermal thickness of H\&E staining sections was further assessed by ImageJ software (National Institutes of Health, Bethesda, MD, USA). For immunohistochemical images, the skin tissue sections were then exposed to $\mathrm{HCl}(3.5 \mathrm{M})$ for $20 \mathrm{~min}$ at room temperature and washed using PBS for 3 times. Subsequently, the skin tissue sections were treated with peroxidase $(0.3 \%)$ to diminish endogenous peroxidase activity. Then, tissue sections were incubated with normal goat serum (5\%) for $30 \mathrm{~min}$ followed by incubation with primary antibodies (anti-p53 antibody, ab131442; Abcam) at 1:100 dilution for $2 \mathrm{~h}$ at room temperature. The section was then incubated with HRP-conjugated compact polymer systems. Diaminobenzidine (DAB; ChemService, West Chester, PA, USA) was used as the chromogen according to the manufacturer's instructions. Apoptosis assay of tissue samples was determined by TUNEL using an In Situ Cell Death Detection kit, Fluorescein (Roche Applied Science, USA) following the manufacturer's protocol. Tumor tissue sections were counterstained with hematoxylin. Then, the number of TUNEL-positive cells was evaluated under a microscope. The ratio of apoptotic cells was determined by the ratio of the apoptotic cells to total cells.

As for the fluorescence assays, the cells were carefully harvested after various treatments and then fixed in $4 \%$ paraformaldehyde for $30 \mathrm{~min}$. Then, the cells were incubated with primary antibody (p-NF- $\mathrm{kB}$; Abcam) at $4^{\circ} \mathrm{C}$ overnight. Fluorophore-conjugated secondary antibodies were treated for $1 \mathrm{~h}$ at $25^{\circ} \mathrm{C}$. The skin tissue sections were dried for $10 \mathrm{~min}$ at room temperature, fixed with chilled acetone for $10 \mathrm{~min}$ at $-20^{\circ} \mathrm{C}$, and washed with PBS for three times (5 min each). The pre-incubation was conducted with $5 \%$ normal rabbit serum at room temperature for $1 \mathrm{~h}$, and sections were incubated with specific antibody: polyclonal rabbit anti-p-NF-kB (1:50; Abcam, Cambridge, MA, USA) at $4^{\circ} \mathrm{C}$ overnight. The Alexa Fluor 488 and 594 labeled anti-rabbit secondary antibodies (Invitrogen) were used in this part. Sections were then subjected to immunofluorescence staining via epifluorescence microscopy (Sunny Co.).

Real-time quantitative ( $q P C R)$ and reverse transcription $P C R$ assays. Total RNA was isolated from the skin tissue samples and $\mathrm{HaCaT}$ cells after various treatments using TRIzol reagent (KeyGen Biotech Co., Ltd.). Reverse transcription PCR was conducted using the PrimeScript RT Reagent kit (Takara Biotechnology Co., Ltd., Dalian, China) following the manufacturer's instructions and cDNA was then used as the template for the subsequent reactions. qPCR was conducted with SYBR Premix Ex Taq II obtained from Takara. The ABI-PRISM 7500 Sequence Detection System (Applied Biosystems Life Technologies, Foster City, CA, USA) was used according to the manufacturer's instructions. The primer sequences used in our study were commercially synthesized and are as follows. The mRNA level of GAPDH was used as the loading control. The $2^{-\Delta \Delta C q}$ analyzing method was applied to evaluate the fold changes in mRNA levels in each group. The primers were as follows: TNF- $\alpha$ forward, 5'-CGA AAG GGA GTA GAA GTG CG-3' and reverse, 5'-AAA CAT ACA GAG CCG GCT AGC C-3'; IL-1 $\beta$ forward, 5'-ACA TAG AGA GGG AGT ACA C-3' and reverse, 5'-CAG CGT AGA TTA CTA GTT CG-3'; IL-6 forward, 5'-GAG AGA CGG AGT GGC CAC and reverse, 5'-CTC AAG TGA GAA GAG GCA ACG GTA GT-3'; IL-18 forward, 5'-CTG ATG AGC GGT CAC AAG AAC-3' and reverse, 5'-TTC TCT AAC GCG TTA AGA GGA C-3'; TGF- $\beta 1$ forward, 5'-TCG TGG AGC TCG AAG AAC AC-3' and reverse, 5-TGG CTG ACT TCA CAA CAG CGT A-3'; GAPDH forward, 5'-AAC GGT GTC ACA GAC AGG CTC A-3' and reverse, 5-TCC ACC TGA CAC GAC ACA ACA-3'.

Western blot analysis. The western blot analysis was performed as previously described (36). Briefly, after treatments under different conditions, the skin cells were colllected and the medium was removed. Then, cells were washed with ice-cold PBS three times and lysed in ice-cold lysis buffer (pH 7.4, $50 \mathrm{mM}$ Tris- $\mathrm{HCl}, 150 \mathrm{mM} \mathrm{NaCl}, 1 \mathrm{mM}$ $\mathrm{NaF}, 1 \mathrm{mM}$ ethyleneglycol-bis(aminoethylether)-tetraacetic acid, $1 \%$ NP-40, $1 \mathrm{mM}$ phenylmethane-sulfonyl fluoride, and $10 \mu \mathrm{g} / \mathrm{ml}$ leupeptin) in the presence of fresh protease inhibitor cocktail. Frozen dorsal skins and epidermal and tumor of mice were obtained from the experimental mice treated under various conditions. Approximately $100 \mathrm{mg}$ tissue sample was lysed with $1 \mathrm{ml}$ lysis buffer. The cell lysates were centrifuged at $15,000 \mathrm{x}$ g for $15 \mathrm{~min}$ at $4^{\circ} \mathrm{C}$ to collect the supernatant. BSA protein assay kit (Thermo Fisher Scientific, Inc.) was used to calculate the protein concentrations following the manufacturer's instructions. Protein extracts $(40 \mathrm{ng})$ were separated by $10 \%$ SDS-PAGE and were then transferred to polyvinylidene fluoride membrane (PVDF; Millipore, Billerica, MA, USA). The PVDF membranes with proteins were blocked with $5 \%$ skim fat dry milk in $0.1 \%$ Tween-20 in Tris-buffered saline (TBS) for $2 \mathrm{~h}$ to block the non-specific sites on the blots. The primary antibodies dissolved in blocking buffer were used to detect the target protein blots at $4^{\circ} \mathrm{C}$ overnight for incubation. The bands on the PVDF membranes were visualized using chemiluminescence with Pierce ECL Western Blotting Substrate reagents (Thermo Fisher Scientific, Inc.). All experiments were performed in triplicate and carried out three times independently. The primary antibodies used in our study included: anti-p21 (1:1,000, ab86696), anti-PUMA (1:1,000, ab9643), anti-Bax (1:1,000, ab32503), anti-p53 (1:1,000, ab131442), anti-caspase-3 (1:1,000, ab90437), anti-IкB $\alpha$ (1:1,000, ab32518), anti-p-IкB $\alpha(1: 1,000$, ab133462), antiNF-kB (1:1,000, ab16502), anti-p-NF-kB (1:1,000, ab86299) and GAPDH (1:1,000, ab8245) all from Abcam.

Statistical analysis. Data are expressed as the mean \pm standard error of the mean (SEM). Statistical analyses were carried out by GraphPad Prism (version 6.0; GraphPad software) by ANOVA with Dunnet's least significant difference post hoc tests. $\mathrm{P}<0.05$ was considered to indicate a statistically significant result. 


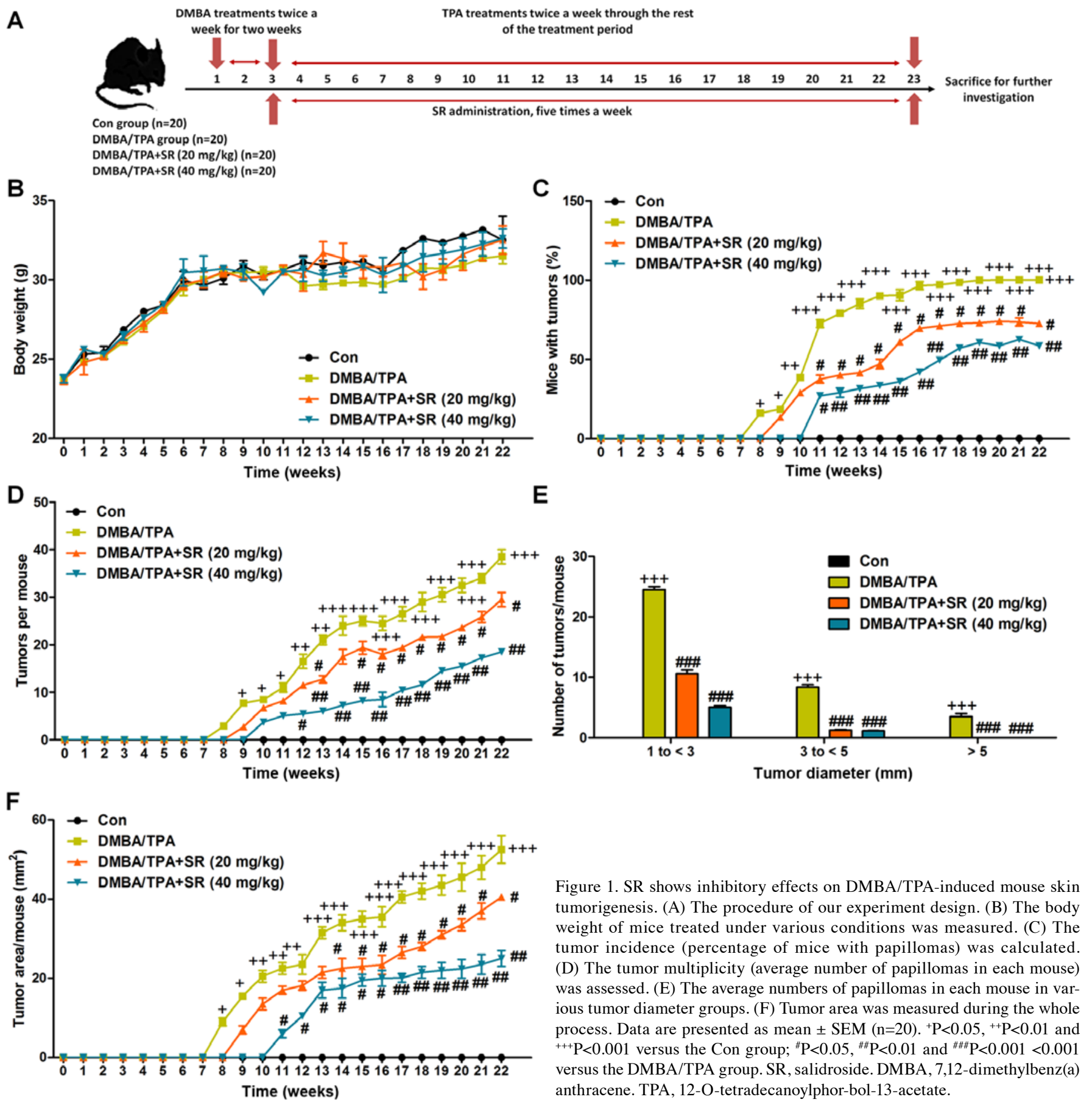

\section{Results}

SR shows inhibitory effects on DMBA/TPA-induced mouse skin tumorigenesis. In order to explore the chemopreventive effect of SR, DMBA-initiated and TPA-promoted mouse skin carcinogenesis in mice was first established in vivo. Fisrt, the body weight of mice was measured, and no significant difference was observed among the different groups, although reduced body weight was exerted in the DMBA/TPA-treated group (Fig. 1B). Compared to the Con group, DMBA/ TPA-induced mice showed a significantly high incidence of papillomas, which was reduced by SR (Fig. 1C). In addition, DMBA/TPA exposure triggered a higher multiplicity of skin papilloma formation that was suppressed in the mice treated

with SR, exhibiting a reduced number of tumors per mouse (Fig. 1D). Furthermore, the suppressive effect of SR on tumorigenesis was supported by the papilloma size distribution (Fig. 1E). Consistently, tumor area was increased by DMBA/ TPA exposure, which was reduced after SR administration with an increase in time (Fig. 1F). Consistently, the tumor area was elevated by DMBA/TPA treatment, which was reduced after SR administration with the increase of time (Fig. 1F). In addition, the histological analysis further revealed that SR markedly ameliorated the increase in epidermal thickness (hyperplasia) in mice with DMBA/TPA induction (Fig. 2). In conclusion, the animal study above strongly indicated that SR efficiently prevented skin carcinogenesis induced by DMBA/TPA and TPA in mice. 

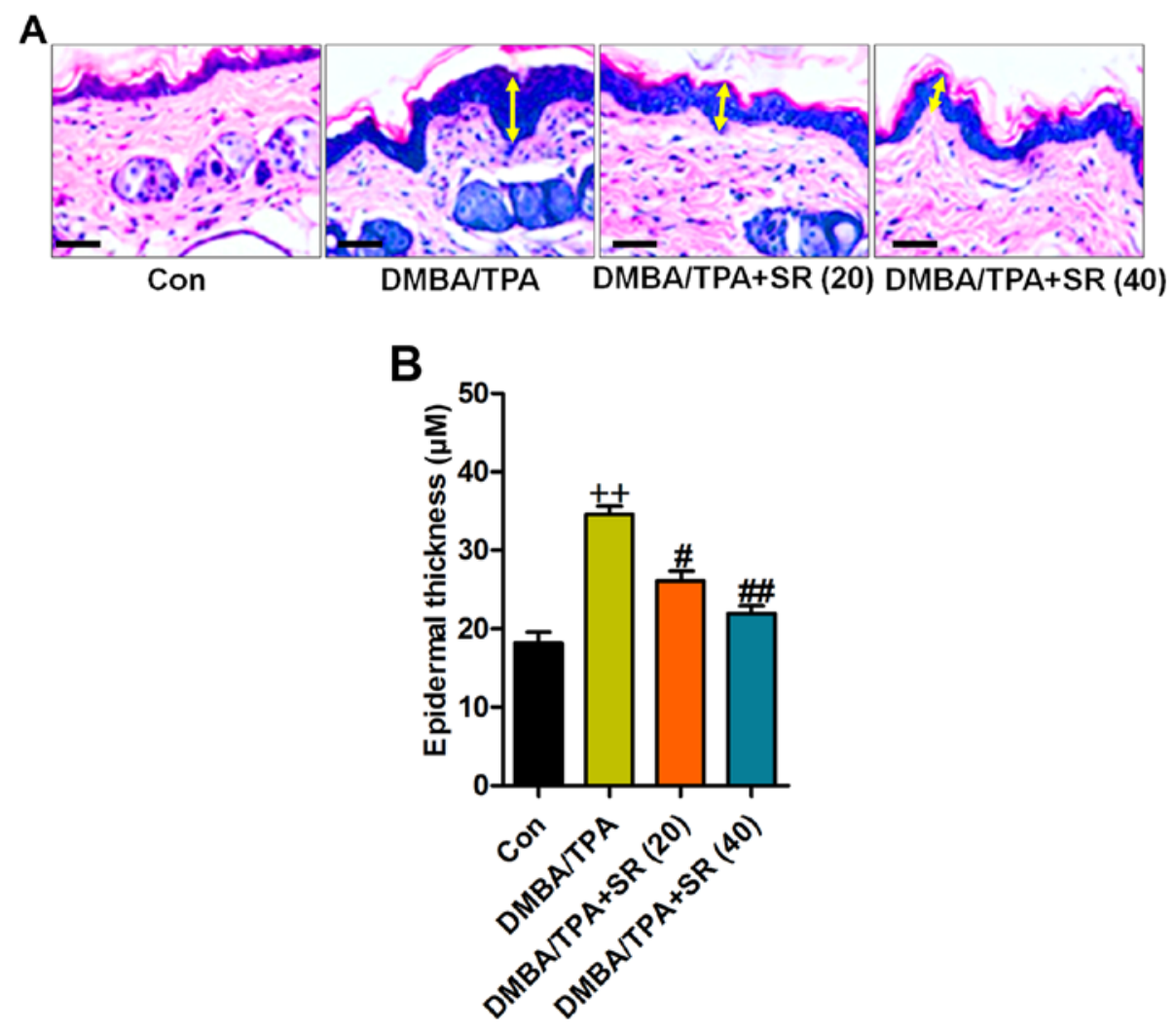

Figure 2. Effects of SR on the histology of mouse skin carcinogenesis induced by DMBA/TPA. (A) Representative images of epidermal proliferation and hyperplasia in the DMBA/TPA-induced mice with different concentrations of SR treatments (20 and $40 \mathrm{mg} / \mathrm{kg}$ ) analyzed by H\&E staining. (B) Quantification of epidermal thickness following H\&E staining. Data are presented as mean $\pm \mathrm{SEM}(\mathrm{n}=20) .{ }^{+} \mathrm{P}<0.05,{ }^{++} \mathrm{P}<0.01$ and ${ }^{+++} \mathrm{P}<0.001$ vs. the Con group; ${ }^{\#} \mathrm{P}<0.05$, ${ }^{\# \#} \mathrm{P}<0.01$

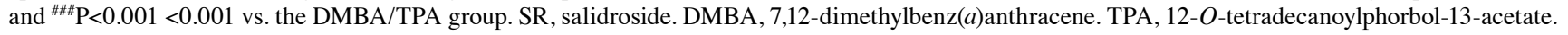

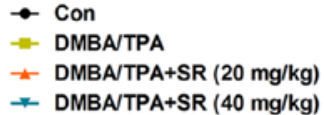

* DMBA/TPA+SR $(40 \mathrm{mg} / \mathrm{kg})$

A

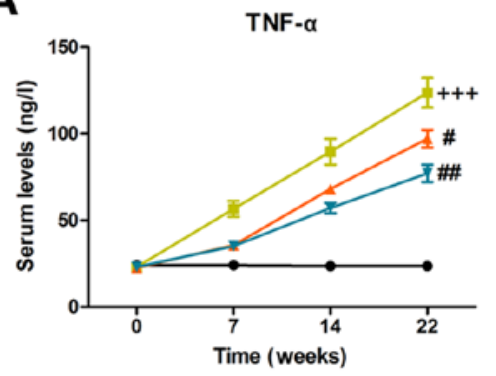

D

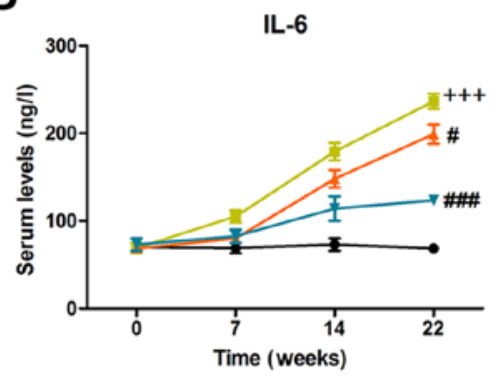

B

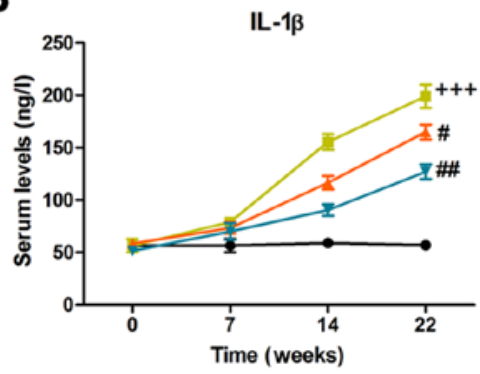

E

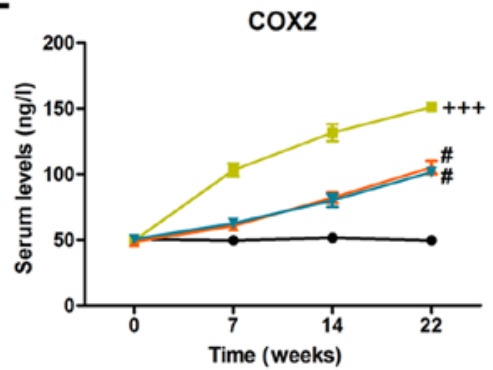

C

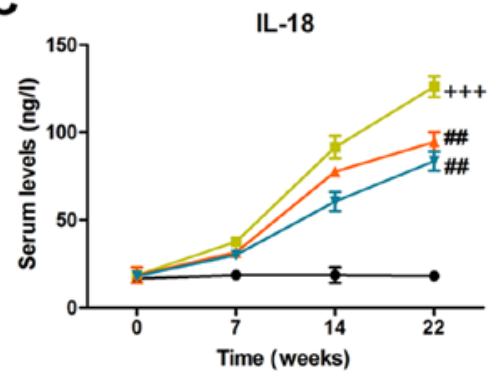

$\mathbf{F}$

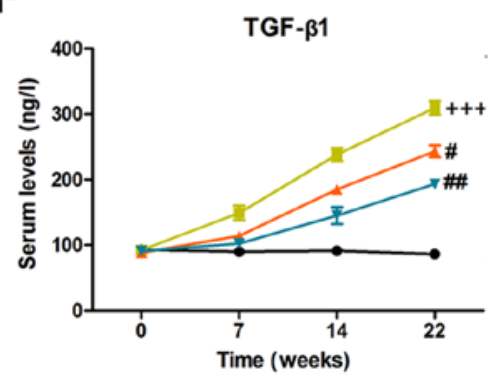

Figure 3. SR suppresses pro-inflammatory cytokine release in the serum of mice with DMBA/TPA induction. The levels of circulating pro-inflammatory cytokines of (A) TNF- $\alpha$, (B) IL-1 $1 \beta$, (C) IL-18, (D) IL-6, (E) COX2 and (F) TGF- $\beta 1$ were evaluated by ELISA methods. Data are presented as mean \pm SEM $(\mathrm{n}=20) .{ }^{+} \mathrm{P}<0.05,{ }^{++} \mathrm{P}<0.01$ and ${ }^{++} \mathrm{P}<0.001$ vs. the Con group; ${ }^{\#} \mathrm{P}<0.05,{ }^{* \#} \mathrm{P}<0.01$ and ${ }^{\# \#} \mathrm{P}<0.001<0.001$ vs. the DMBA/TPA group. SR, salidroside. DMBA, 7,12-dimethylbenz $(a)$ anthracene. TPA, 12- $O$-tetradecanoylphor-bol-13-acetate. 


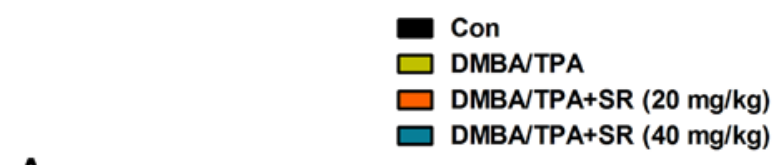

A

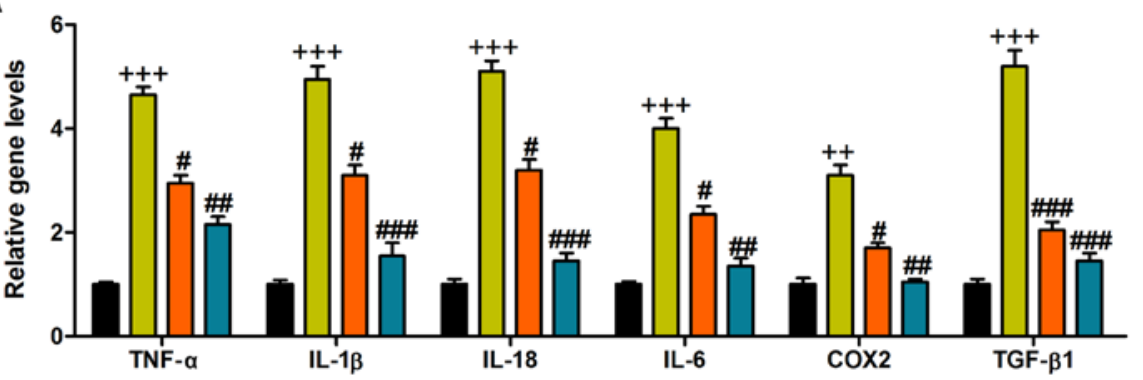

B

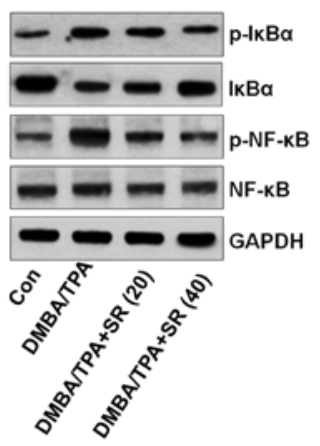

C
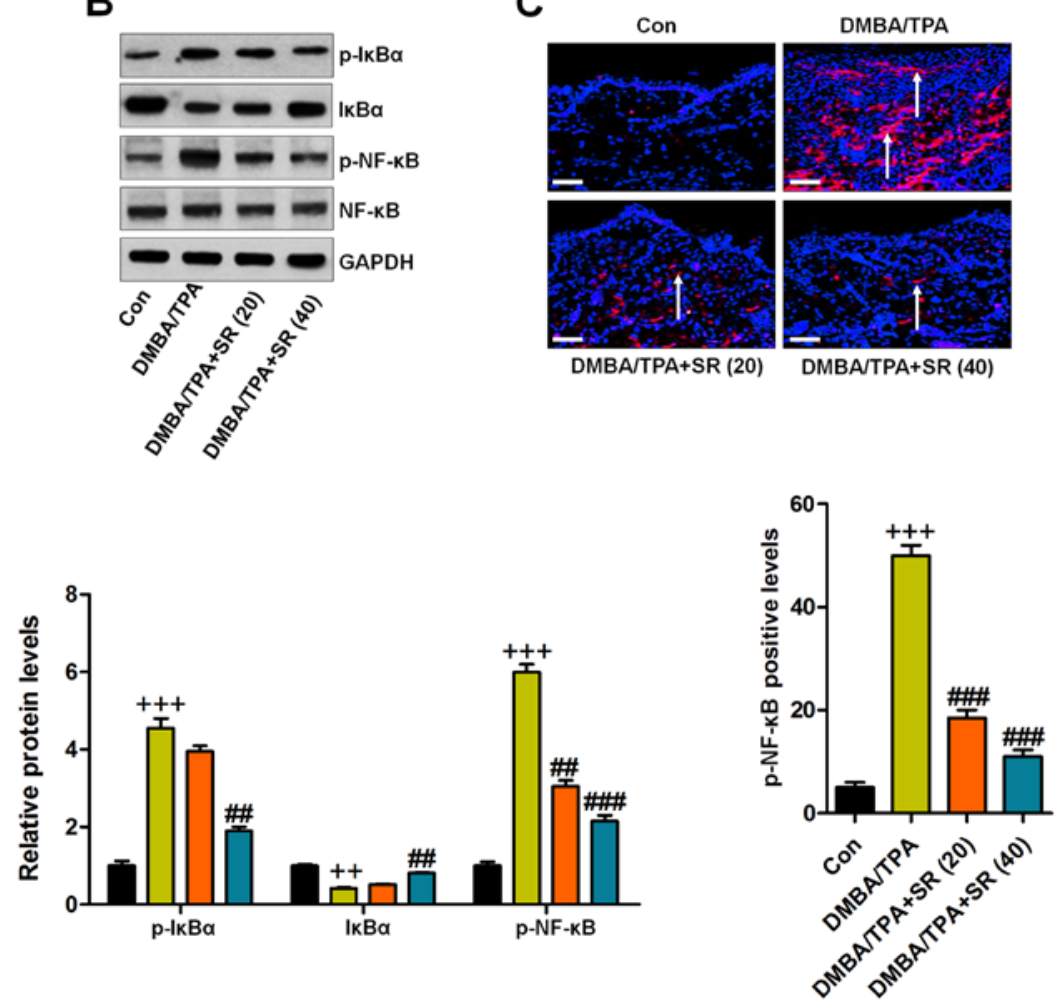

Figure 4. SR reduces DMBA/TPA-induced inflammation in the skin of mice through inactivation of NF- $\kappa \mathrm{B}$ in vivo. The skin was removed from mice treated under different conditions. Then, (A) RT-qPCR analysis was used to determine TNF- $\alpha$, IL-1 $\beta$, IL- 18 , IL-6, COX2 and TGF- $\beta 1$ mRNA levels. (B) Western blot analysis was carried out to evaluate phosphorylated $\mathrm{I} \kappa \mathrm{B} \alpha, \mathrm{I} \kappa \mathrm{B} \alpha$ and phosphorylated NF- $\kappa \mathrm{B}$ in the skin tissue samples obtained from mice. (C) Representative images of skin after exposure to DMBA/TPA in the absence or presence of SR. The quantification of phosphorylated NF- $\kappa \mathrm{B}$ was measured using immunofluorescence analysis. Data are presented as mean \pm SEM $(\mathrm{n}=20) .{ }^{+} \mathrm{P}<0.05,{ }^{++} \mathrm{P}<0.01$ and ${ }^{++} \mathrm{P}<0.001$ vs. the Con group; ${ }^{\#} \mathrm{P}<0.05,{ }^{\# \#} \mathrm{P}<0.01$ and ${ }^{\# \# \#} \mathrm{P}<0.001<0.001$ vs. the DMBA/TPA group. SR, salidroside. DMBA, 7,12-dimethylbenz $(a)$ anthracene. TPA, 12- $O$-tetradecanoylphor-bol-13-acetate.

SR suppresses the secretion of pro-inflammatory cytokines in the serum of mice following DMBA/TPA induction. Pro-inflammatory cytokines were also determined to assess the role of SR in DMBA/TPA-induced mice with skin cancer. As shown in Fig. 3A, serum TNF- $\alpha$ was higher in the DMBA/ TPA-treated mice, which was enhanced with increasing time. SR also significantly suppressed TNF- $\alpha$ expression. Next, cytokines IL-1 $\beta$ (Fig. 3B), IL-18 (Fig. 3C), IL-6 (Fig. 3D), COX2 (Fig. 3E) and TGF- $\beta 1$ (Fig. 3F) were all observed to have elevated expression in the DMBA/TPA-treated mice, which were suppressed by SR during the treatment procedure. Taken together, the findings above indicated that SR has a potential role in blocking the secretion of pro-inflammatory cytokines.
$S R$ reduces $D M B A / T P A$-induced inflammation in the skin of mice by inactivating $N F-\kappa B$ in vivo. Next, we attempted to ascertain whether the $\mathrm{NF}-\kappa \mathrm{B}$ signaling pathway is also involved in SR-ameliorated skin cancer induced by DMBA/ TPA. As shown in Fig. 4A, RT-qPCR analysis further indicated that pro-inflammatory cytokines, including TNF- $\alpha$, IL-1 $\beta$, IL-18, IL-6, and COX2, as well as anti-inflammatory factor TGF- $\beta 1$, were increased in the tissue samples of DMBA/TPA-induced mice, which were all reduced by $\mathrm{SR}$ administration in a dose-dependent manner. The I $\mathrm{B} /$ $\mathrm{NF}-\kappa \mathrm{B}$ signaling pathway was also explored. The data indicated that I $\kappa \mathrm{B} \alpha$ phosphorylation was upregulated in the DMBA/TPA-treated mice, while I $\kappa \mathrm{B} \alpha$ was downregulated. 

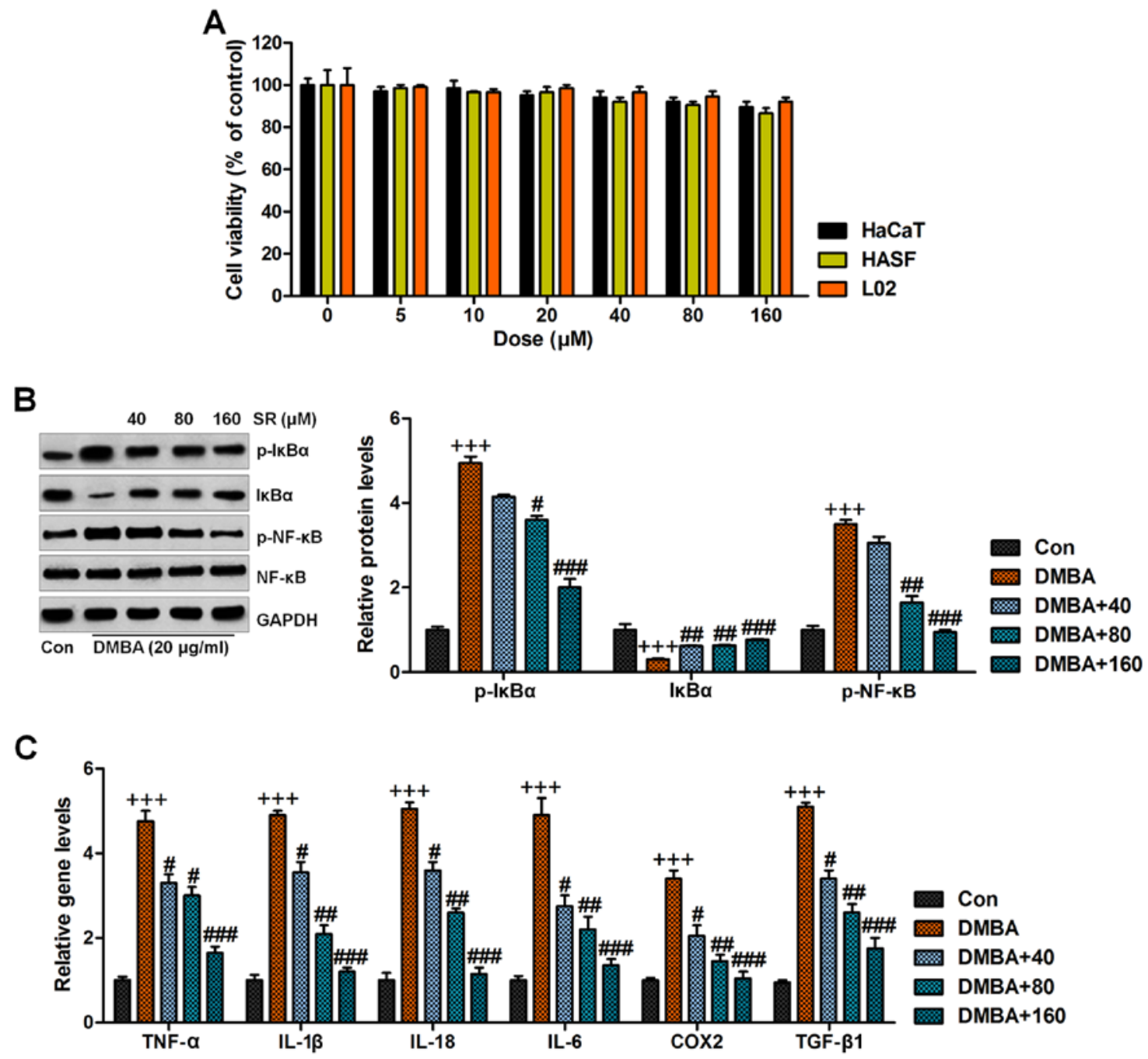

D

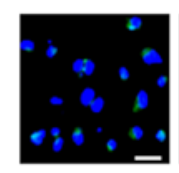

Con
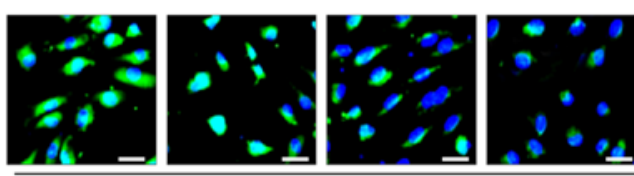

DMBA

$80(\mu \mathrm{M})$ $160(\mu \mathrm{M})$

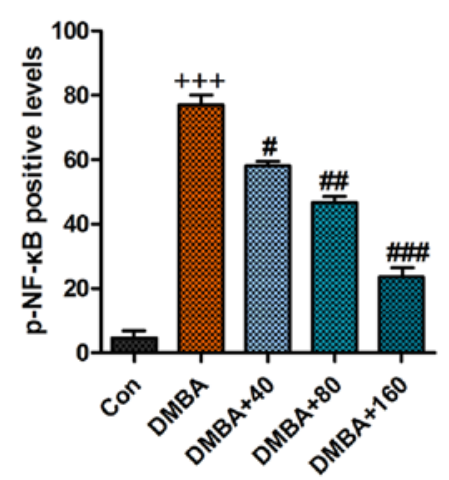

Figure 5. SR suppresses the inflammation response in DMBA-induced cells in vitro. (A) Normal human epidermal keratinocytes, HaCaT, human hypertrophic scar fibroblasts (HSFs) and human normal liver cell line L02 were treated with different concnetrations of SR (0, 5, 10, 20, 40, 80 and $160 \mu \mathrm{M})$ for $48 \mathrm{~h}$. Then, all cells were harvested for MTT assay. Normal human epidermal keratinocytes, HaCaT, were treated with $20 \mu \mathrm{g} / \mathrm{ml} \mathrm{DMBA}$ for $48 \mathrm{~h}$ with or without SR treatment at 40,80 and $160 \mu \mathrm{M}$. Then, all cells were harvested for the following research. (B) Western blot analysis was used to determine levels in phosphorylated

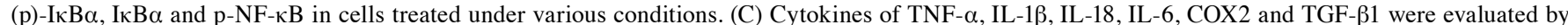
RT-qPCR analysis. (D) The immunofluorescence analysis was used to assess $\mathrm{NF}-\kappa \mathrm{B}$ phosphorylation. Data are presented as mean $\pm \mathrm{SEM}(\mathrm{n}=10)$. ${ }^{+} \mathrm{P}<0.05$, ${ }^{++} \mathrm{P}<0.01$ and ${ }^{+++} \mathrm{P}<0.001$ vs. the Con group; ${ }^{\#} \mathrm{P}<0.05,{ }^{\#} \mathrm{P}<0.01$ and ${ }^{\# \# \#} \mathrm{P}<0.001<0.001$ vs. the DMBA group. SR, salidroside. DMBA, $7,12-$ dimethylbenz $(a)$ anthracene. TPA, 12-O-tetradecanoylphorbol-13-acetate.

Phosphorylated NF- $\kappa \mathrm{B}$ levels were also elevated due to DMBA/TPA induction in mice (Fig. 4B). Of note, SR exerted an inhibitory effect on $\mathrm{I} \kappa \mathrm{B} \alpha$ and $\mathrm{NF}-\kappa \mathrm{B}$ phosphorylation, indicating its anti-inflammatory property. Furthermore, the immunofluorescence analysis revealed that enhanced $\mathrm{NF}-\kappa \mathrm{B}$ phosphorylated levels by DMBA/TPA were reduced after SR administration (Fig. 4C). Together, the results above demonstrated that SR inhibited skin carcinogenesis by impeding inflammation, linked to the suppression of the I $\mathrm{B} \alpha / \mathrm{NF}-\kappa \mathrm{B}$ signaling pathway. 
A

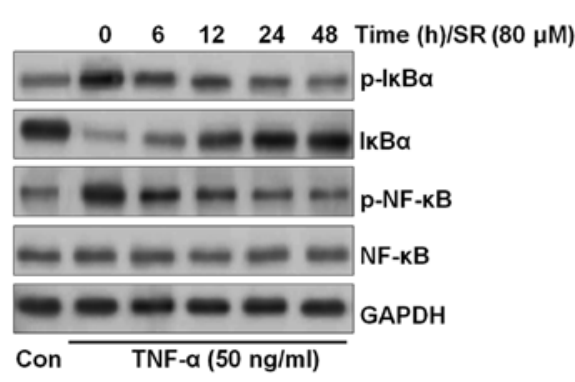

C

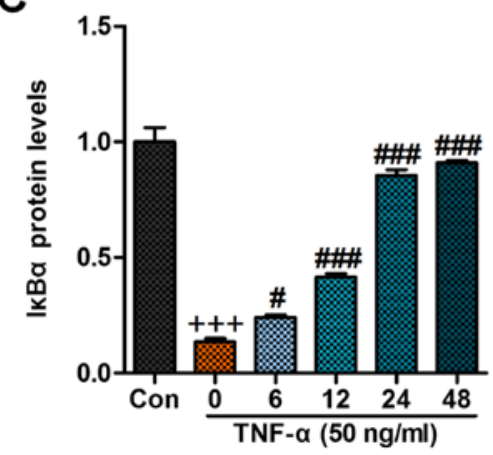

B

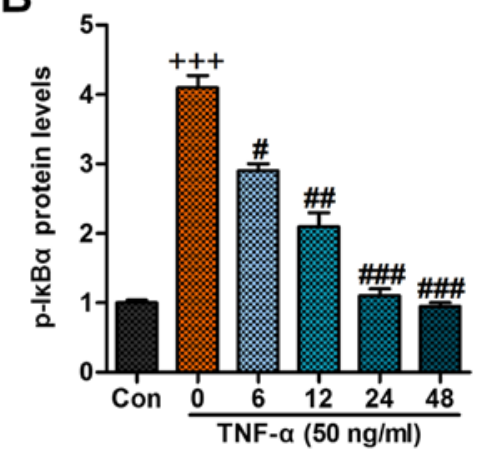

D

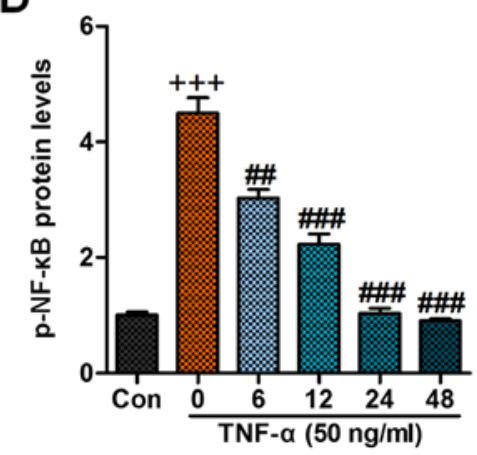

Figure 6. SR-mediated suppression of inflammation response in cells is time-dependent. Normal human epidermal keratinocytes (HaCaT) were pre-treated with $80 \mu \mathrm{M}$ SR for the indicated time. Then, all cells were exposed to TNF- $\alpha$ at $50 \mathrm{ng} / \mathrm{ml}$ for $1 \mathrm{~h}$. (A) The representative images of protein bands of

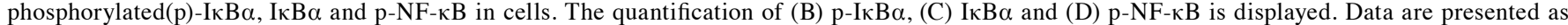
mean \pm SEM $(n=10) .{ }^{+} \mathrm{P}<0.05,{ }^{++} \mathrm{P}<0.01$ and ${ }^{+++} \mathrm{P}<0.001$ vs. the Con group; ${ }^{\#} \mathrm{P}<0.05,{ }^{\# \#} \mathrm{P}<0.01$ and ${ }^{\# \# \#} \mathrm{P}<0.001<0.001$ vs. the TNF- $\alpha$ group. SR, salidroside.

SR suppresses the inflammation response in DMBA-induced cells in vitro. As it was described above, we found that inflammation blockage by SR might be a possible molecular mechanism by which to prevent skin carcinogenesis progression in DMBA/TPA-induced mice in vivo. In order to further confirm our findings above, the in vitro study was conducted. First MTT assays were used to calculate the safety of SR to normal cells. The results indicated that compared to the group in the absence of any treatment, no significant difference was observed among the various groups of treated cells as indicated (Fig. 5A). Thus, we supposed that SR might be safe for application with little cytotoxicity to normal cells. Normal human epidermal keratinocytes, $\mathrm{HaCaT}$, were treated with $20 \mu \mathrm{g} / \mathrm{ml}$ DMBA for $48 \mathrm{~h}$ in the absence or presence of SR at 40, 80 and $160 \mu \mathrm{M}$. As shown in Fig. 5B, we found that cells exposed to DMBA displayed accelerated $\mathrm{I} \kappa \mathrm{B} \alpha$ phosphorylation and reduced $\mathrm{I} \kappa \mathrm{B} \alpha$ expression, which were reversed by $\mathrm{SR}$ administration. NF- $\kappa$ B was also activated by DMBA exposure. Significantly, SR treatment dose-dependently reduced $\mathrm{NF}-\kappa \mathrm{B}$ activity in the cells. RT-qPCR analysis indicated that SR suppressed high levels of pro-inflammatory cytokines, including TNF- $\alpha$, IL- $1 \beta$, IL-18, IL-6, and COX2, and TGF- $\beta 1$ was also found to be reduced, indicating the attenuated inflammatory response, which were in line with the in vivo results (Fig. 5C). Moreover, the immunofluorescence assays also showed that SR reduced NF- $\kappa \mathrm{B}$ phosphorylation caused by DMBA in normal human epidermal keratinocytes (Fig. 5D). Next, to further illustrate the role of SR in suppressing inflammation, the cells were pre-treated with SR $(80 \mu \mathrm{M})$ for different times, ranging from 0 to $48 \mathrm{~h}$. Then, they were exposed to
$50 \mathrm{ng} / \mathrm{ml} \mathrm{TNF}-\alpha$ for another $1 \mathrm{~h}$ to induce inflammation. The western blot analysis indicated that $\mathrm{I} \kappa \mathrm{B} \alpha$ and $\mathrm{NF}-\kappa \mathrm{B}$ were activated, which were markedly reduced by $\mathrm{SR}$ administration in a time-dependent manner (Fig. 6A, B and D). Oppositely, the downregulated level of $\mathrm{I} \kappa \mathrm{B} \alpha$ due to TNF- $\alpha$ exposure was reversed by SR treatment (Fig. 6A and C). In conclusion, the data above indicate that SR, indeed, suppressed the inflammatory response in DMBA-treated cells or skin tissue samples, exhibiting its preventive effects on skin carcinogenesis.

SR prevents skin carcinogenesis through apoptosis induction in mice in vivo. Immunohistochemical analysis indicated that in the skin tissue samples of the DMBA/TPA-induced mice reduced TUNEL levels were noted when compared to the control group, revealing that the apoptotic response might be disrupted following DMBA/TPA treatment. In contrast, SR treatment significantly enhanced the percentage of TUNELpositive cells, suggesting cell death during skin carcinogenesis (Fig. 7A and B). p53, an essential tumor suppressor, was found to be downregulated by DMBA/TPA, and in agreement with TUNEL alterations, SR administration reversed the p53 reduction (Fig. 7A and $\mathrm{C}$ ). Additionally, western blot analysis illustrated that DMBA/TPA reduced p53 expression, while SR augmented p53 protein expression levels (Fig. 7D). In summary, the data above indicated that apoptosis might be involved in SR-regulated skin carcinogenesis caused by DMBA/TPA.

SR induces apoptosis in DMBA-induced cells in vitro. $\mathrm{p} 53$ can induce apoptosis, which is linked to Bax or other pro-apoptotic molecules (37). Therefore, we analyzed the expression of these 
A

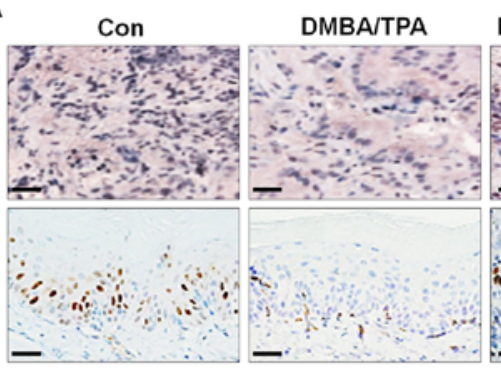

DMBA/TPA+SR (20) DMBA/TPA+SR (40)

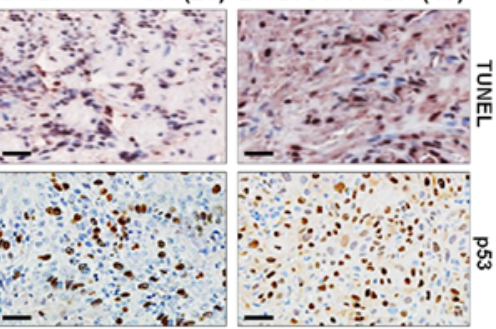

D

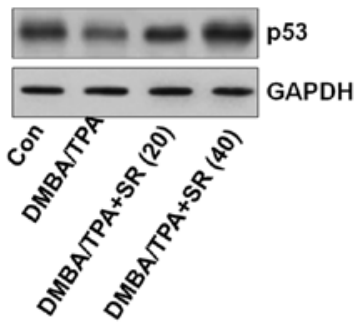

B

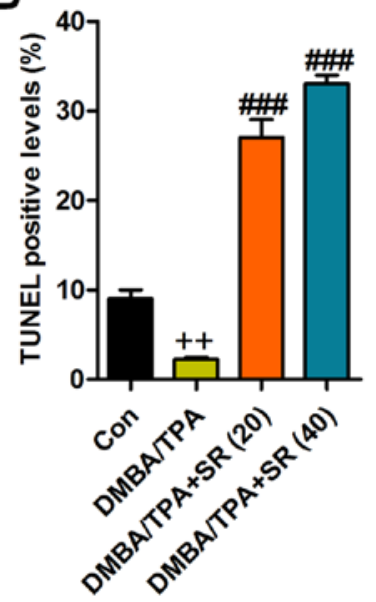

C

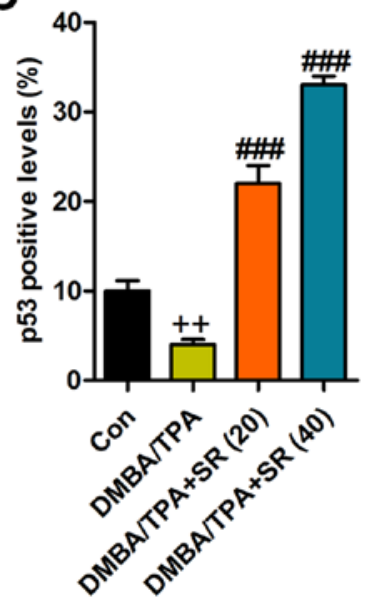

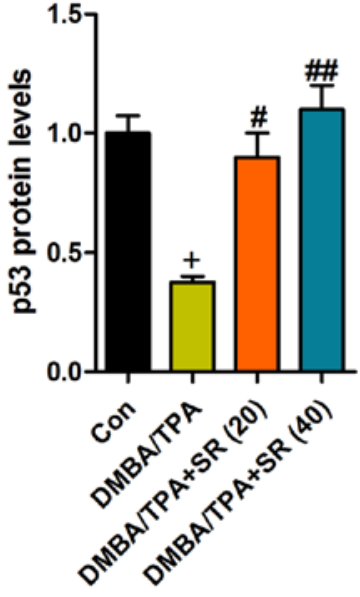

Figure 7. SR prevents skin carcinogenesis through induction of apoptosis in mice in vivo. (A) Immunohistochemical analysis was used to calculate TUNEL and p53 levels in the skin tissue samples obtained from mice following different treatments. The quantification of (B) TUNEL and (C) p53 was evaluated following the immunohistochemical assays. (D) Western blot analysis was used to calculate p53 expression levels in tissue samples. Data are presented as mean \pm SEM $(\mathrm{n}=20) .{ }^{+} \mathrm{P}<0.05,{ }^{++} \mathrm{P}<0.01$ and ${ }^{++} \mathrm{P}<0.001$ vs. the Con group; ${ }^{\#} \mathrm{P}<0.05,{ }^{\# \#} \mathrm{P}<0.01$ and ${ }^{\# \#} \mathrm{P}<0.001<0.001$ vs. the DMBA/TPA group. SR, salidroside. DMBA, 7,12-dimethylbenz $(a)$ anthracene. TPA, 12- $O$-tetradecanoylphorbol-13-acetate.
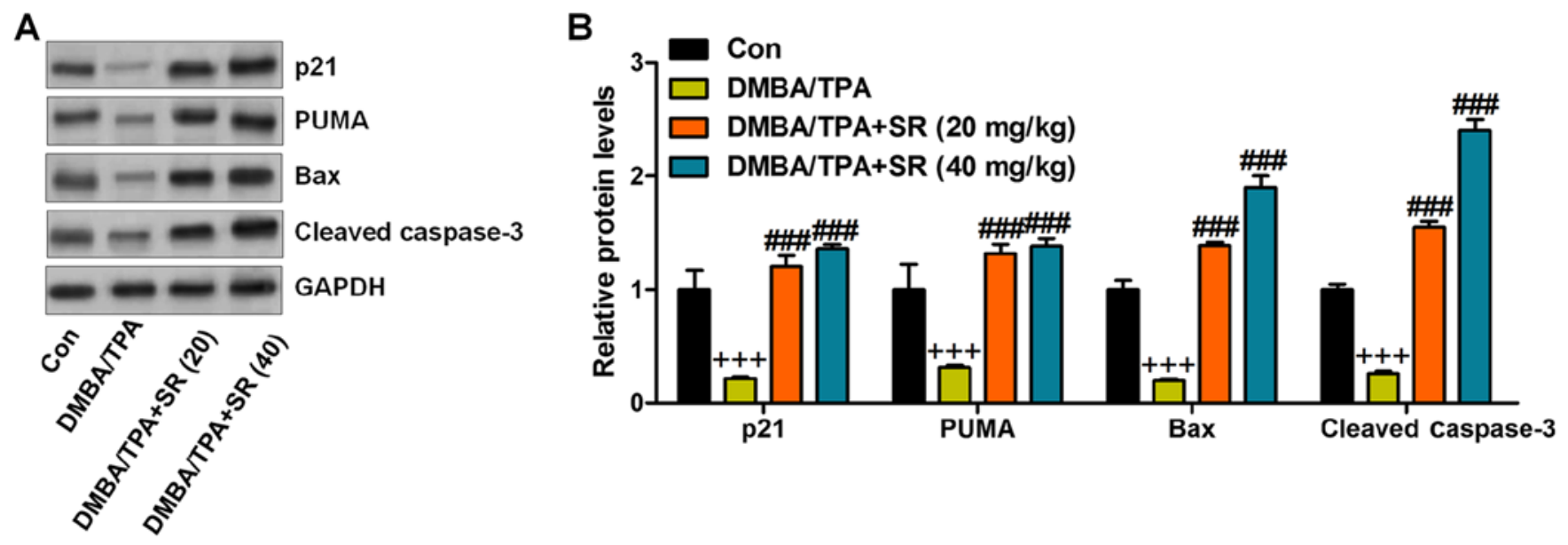

Figure 8. SR promotes apoptosis following DMBA/TPA treatment in mice. (A) The representative images of p21, PUMA, Bax and cleaved caspase-3 protein bands. (B) The quantification of p21, PUMA, Bax and cleaved caspase- 3 is shown. Data are presented as mean \pm SEM $(n=20) .{ }^{+} \mathrm{P}<0.05,{ }^{++} \mathrm{P}<0.01$ and ${ }^{+++} \mathrm{P}<0.001$ vs. the Con group; ${ }^{\#} \mathrm{P}<0.05,{ }^{\# \#} \mathrm{P}<0.01$ and ${ }^{\# \# \#} \mathrm{P}<0.001<0.001$ vs. the DMBA/TPA group. SR, salidroside. DMBA, 7,12-dimethylbenz $(a)$ anthracene. TPA, 12- $O$-tetradecanoylphorbol-13-acetate.

proteins in the skin tissues of mice after various treatments. The immunoblot analysis showed a decrease in p21, PUMA, Bax, and cleaved caspase- 3 in the DMBA/TPA-treated mice, which were significantly reversed by SR (Fig. 8). Next, the in vitro study was conducted to further confirm our data above. Human normal epidermal keratinocytes, HaCaT, exposed to DMBA were treated with or without SR at the indicated concentrations. Then, flow cytometric analysis indicated that DMBA caused reduced percentages of apoptotic cells, which was in line with the TUNEL assays in vivo. Notably, SR treatment enhanced apoptosis in the DMBA-treated cells (Fig. 9A and B). Finally, pro-apoptotic signals of p21, PUMA, Bax and cleaved caspase-3 protein levels were also reduced by DMBA in vitro, which were elevated after SR administration, 
A

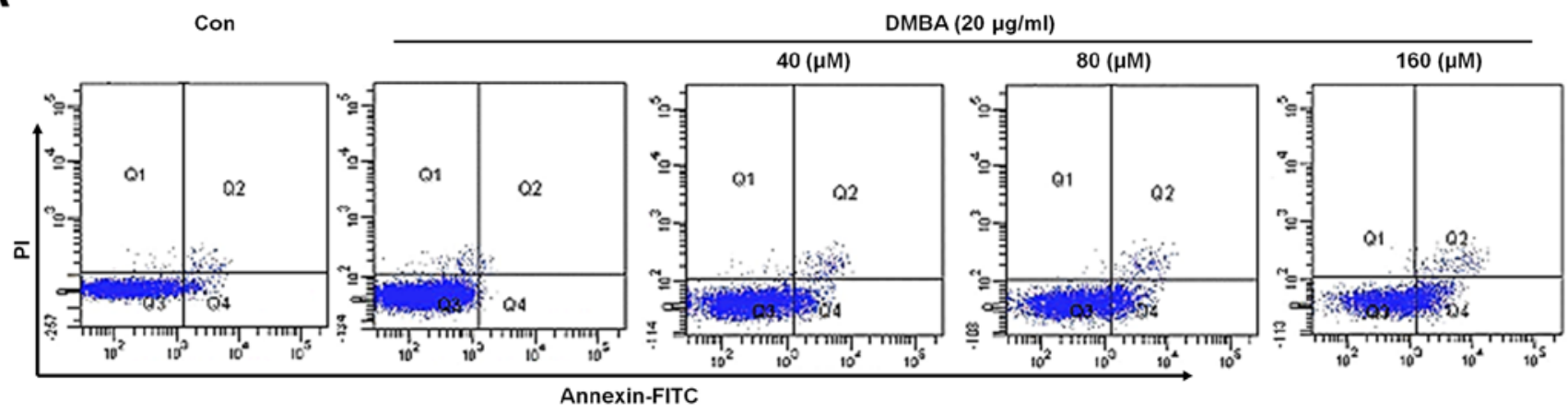

B

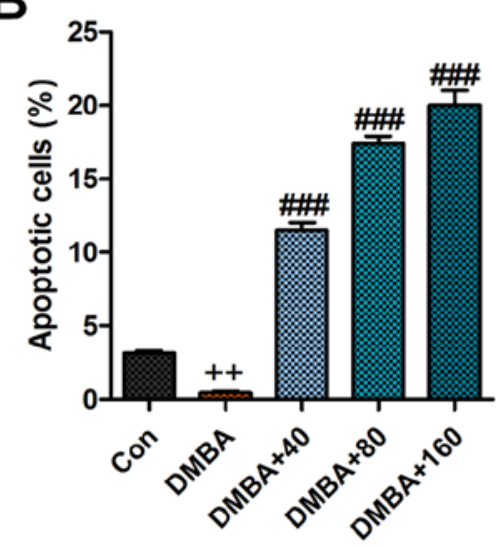

C

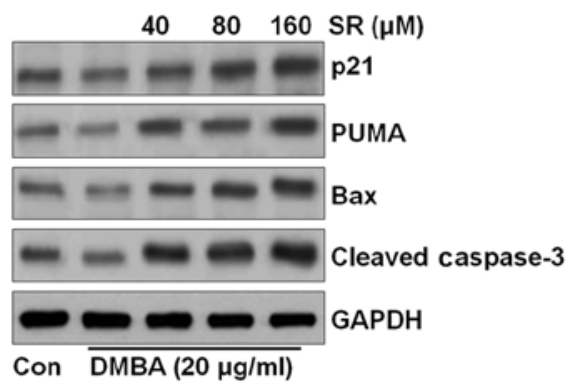

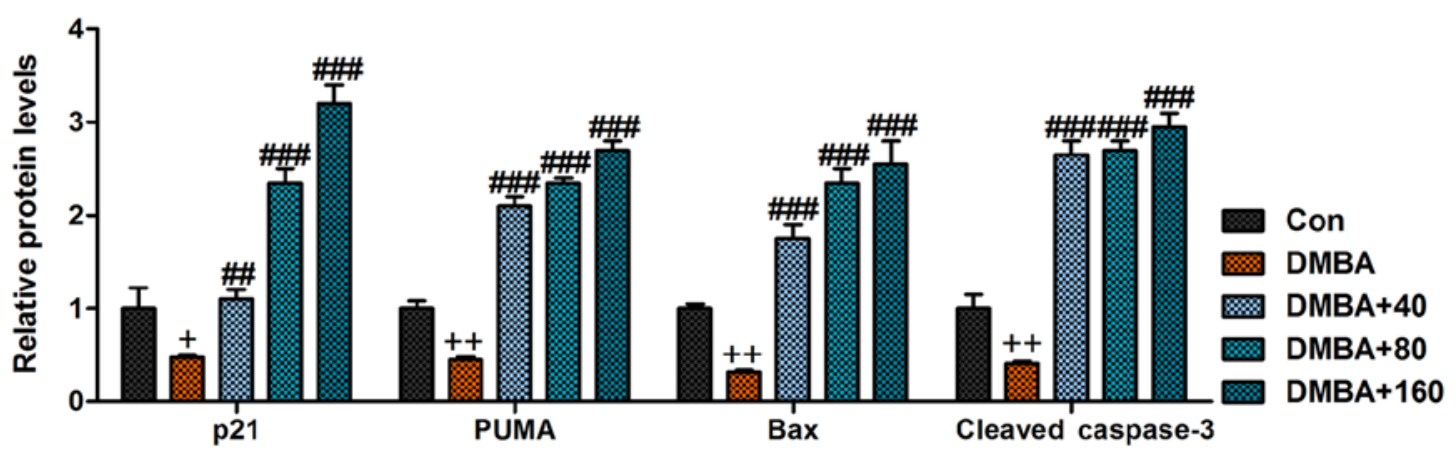

Figure 9. SR induces apoptosis in DMBA-exposed cells in vitro. (A) Flow cytometric analysis was carried out to calculate the apoptotic cells under various treatments. (B) The quantification of apoptotic cells is shown following flow cytometry. (C) Western blot analysis was performed to evaluate p21, PUMA, Bax and cleaved caspase-3 protein levels in cells with DMBA induction accompanied by or without SR administration. Data are presented as mean \pm SEM $(\mathrm{n}=20) .{ }^{+} \mathrm{P}<0.05,{ }^{+} \mathrm{P}<0.01$ and ${ }^{+++} \mathrm{P}<0.001$ vs. the Con group; ${ }^{\#} \mathrm{P}<0.05,{ }^{\# \#} \mathrm{P}<0.01$ and ${ }^{\# \#} \mathrm{P}<0.001<0.001$ vs. the DMBA/TPA group. SR, salidroside. DMBA, 7,12-dimethylbenz $(a)$ anthracene. TPA, 12- $O$-tetradecanoylphor-bol-13-acetate.

indicating the role of SR in inducing apoptosis to avoid skin carcinogenesis in vitro (Fig. 9C).

\section{Discussion}

Non-melanoma skin cancers (NMSCs) are reported as one of the most commonly diagnosed cancers in the world $(1-3,38)$. The chronic exposure to solar UR is a major etiological factor for skin disease. Due to various changes in human life style, the incidence of NMSCs is increasing due to oxidative stress, inflammatory and immunosuppressive factors induced by solar UR exposure $(3,4,39)$. Furthermore, patients with organ transplants are at greater risk to develop skin cancer in comparison to healthy individuals. Because of the rising risk of skin cancer, more effective, safe, potent, and affordable anticancer therapeutic strategies are required to prevent this disease $(40,41)$. In addition, one limitation is that it is difficult to predict the location of the initiation of human skin tumorigenesis. In the present study, we attempted to evaluate the anti-skin cancer effect of SR using DMBA/TPA-induced skin tumors as an in vivo model and human skin epidermal $\mathrm{HaCaT}$ cells, as an in vitro model. Following previous studies, DMBA-initiated and TPA-enhanced mouse skin tumorigenesis is essential for the investigation of cancer prevention. SR is the main effective component of Rhodiola rosea $\mathrm{L}$. with a variety of pharmacologic properties, such as anti-oxidative, anti-aging, 


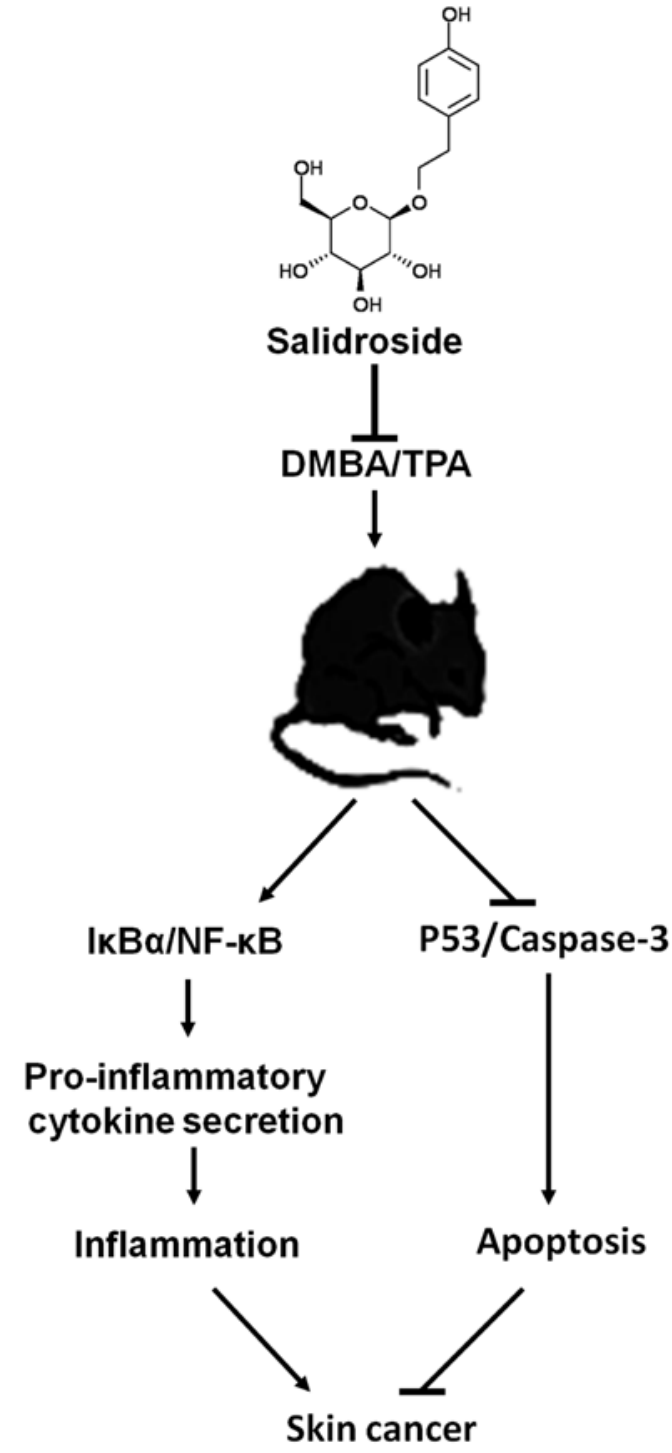

Figure 10. Working model of salidroside (SR) against skin cancer. SR prevents the carcinogenesis of mouse skin tissue initiated by DMBA/TPA. SR acts as a drug to suppress skin tumors in mice by inactivating the I $\mathrm{KB} \alpha$ NF- $\mathrm{kB}$ pathway, thus reducing the secretion of pro-inflammatory cytokines. In addition, the p53 and caspase- 3 signaling pathways were enhanced by SR, resulting in apoptosis to prevent skin carcinogenesis. SR, salidroside. DMBA, 7,12-dimethylbenz( $a$ )anthracene. TPA, 12-O-tetradecanoylphorbol13-acetate.

anti-inflammatory, anticancer, anti-fatigue and anti-depressant activities, to protect tissues or cells from being injured under various stresses $(42,43)$. Here, in the present study in vivo, we found that SR treatment reduced tumor incidence and the total number of tumors in each mouse. In addition, SR-mediated suppression of skin tumors in mice was related to the inactivation of the I $\kappa \mathrm{B} \alpha / \mathrm{NF}-\kappa \mathrm{B}$ pathway, thus decreasing the secretion of pro-inflammatory cytokines. In addition, p53 and caspase-3 signaling pathways were enhanced by SR, leading to apoptosis against skin carcinogenesis. Furthermore, the MTT assay showed little cytotoxicity of SR to normal cells, suggesting its safety for application. Therefore, the results above indicate that SR may be a promising candidate for inhibiting skin cancer.

Pro-inflammatory cytokines, such as IL-1 $\beta$, TNF- $\alpha$, IL-18, IL-6 and COX2, are suggested to play crucial roles in the progression of diseases by inflammation response $(23,44,45)$.
$\mathrm{NF}-\kappa \mathrm{B}$ has been reported to be involved in skin damage, and whose sustained activation has been elucidated in numerous tumors and involved in various stages of carcinogenesis $(24,26,46)$. NF- $\kappa \mathrm{B}$ phosphorylation is crucial for the release of pro-inflammatory cytokines (47). Its activation leads to the subsequent induction of pro-inflammatory cytokines (i.e., TNF- $\alpha$, IL-1 $\beta$ and IL-6), contributing to inflammation response and disease progression (48). Excessive release of TNF- $\alpha$, IL-1 $\beta$, IL-18, IL- 6 and COX2 is associated with the enhanced risk of various diseases, including skin carcinogenesis $(42,45)$. TNF- $\alpha$ was reported to be an inflammatory response primarily, which is related to skin injury (49). IL-1 $\beta$ is generated by macrophages activated as proteins and is also known as catabolin. This cytokine is known as a crucial regulator of the inflammatory response and various cellular functions, including cell differentiation and apoptosis $(50,51)$. $\mathrm{UVB}$, as previously reported, can lead to a high release of COX2. COX2 participates in the inflammatory response, cell survival and proliferation (52). In skin damage induced under various situations, hyper-proliferation of keratinocytes is induced, which has a close relationship with pro-inflammatory cytokine secretion $(52,53)$. Therefore, suppression of the inflammation response is a key to preventing skin tumor, which is also a molecular mechanism for drug exploration (54). Consistently, in our study, we first found that pro-inflammatory cytokines were highly induced by DMBA/TPA in vivo and in vitro, which were significantly reduced by SR administration in a dose-dependent manner. The activated IKK kinase leads to the phosphorylation and degradation of $\mathrm{I} \kappa \mathrm{B}$ in the proteasome, and thereby the release of $\mathrm{NF}-\kappa \mathrm{B}$ from the NF-IKB- $\kappa \mathrm{B}$ complex, enabling the translocation of $\mathrm{NF}-\kappa \mathrm{B}$ to the nucleus, where the expression of genes encoding pro-inflammatory cytokines is induced (55). Furthermore, in our study, we found that the $\mathrm{I} \kappa \mathrm{B} /$ $\mathrm{NF}-\kappa \mathrm{B}$ signaling pathway was markedly activated by DMBA/ TPA treatment, while being inactivated by SR. The data here indicated that the function of SR to prevent skin carcinogenesis might be attributed to suppression of inflammation.

Apoptosis is considered as a key molecular mechanism by which various cancer cells are induced to death $(27,40,41,56)$. Apoptosis is tightly controlled by the balance between pro- and anti-apoptotic members of the Bcl-2 protein family. Changes in the relative expression levels of such molecules will ultimately decide the cell fate (57). Additionally, cysteinyl aspartate specific proteinases (caspases) play important roles during apoptosis (58). Increase in pro-apoptotic molecules, including Bax, helps to induce apoptosis by enhancing caspase-3 cleavage, which has been well known to play an important role in inducing apoptosis (59). Therefore, we subsequently evaluated the protein levels of pro-apoptotic Bax and caspase-3 molecules which define the cell propensity to apoptosis (60). p53, an important tumor suppressor, provides powerful intrinsic defense against various cancers through its diverse function as a major modulator of apoptosis, the cell cycle and senescence $(61,62)$. Abnormalities of p53 have been observed in patients suffering from different cancers (63). Furthermore, p53 shows transcriptional activities to regulate the expression of pro-apoptotic gene: PUMA (64). PUMA is known as the activator for Bax, and is involved in mitochondrial-mediated apoptosis $(65,66)$. p21 is a downstream signal of $\mathrm{p} 53$, which participates in apoptosis induction (67). SR has been confirmed to modulate apoptosis 
in numerous types of injuries, including brain, vascular disease and colon cancer (68-70). SR was observed to promote an apoptotic response to induce cell death, contributing to colon cancer and leukemia prevention. In the present study, western blot analysis indicated that SR upregulated p53, p21, PUMA, Bax and caspase- 3 cleavage, contributing to apoptosis development both in in vivo and in vitro models induced by DMBA/TPA and DMBA, respectively. Furthermore, TUNEL assay of tissue samples and flow cytometry analysis of cells also confirmed the role of SR in apoptosis induction during skin carcinogenesis. Together, our study revealed that triggering apoptosis might be a possible molecular mechanism by which SR showed preventive effects against skin cancer.

In conclusion, we found that SR prevents the carcinogenesis of mouse skin tissue initiated by DMBA/TPA. SR acts as a drug to suppress skin tumors in mice by inactivating the I $\kappa \mathrm{B} \alpha /$ $\mathrm{NF}-\kappa \mathrm{B}$ pathway, thus reducing the secretion of pro-inflammatory cytokines. In addition, p53 and caspase-3 signaling pathways were enhanced by SR, resulting in apoptosis to prevent skin carcinogenesis (Fig. 10). The finding supports the proposal that SR has skin tumor-suppressive activity, which may be a therapeutic strategy for human skin cancer treatment. However, further study is required to confirm its function in patients with skin tumors.

\section{Acknowledgements}

Not applicable.

\section{Funding}

No funding was received.

\section{Availability of data and materials}

The datasets used during the present study are available from the corresponding author upon reasonable request.

\section{Authors' contributions}

YHK did experiments, and SPX did the calculation and wrote the manuscript.

\section{Ethics approval and consent to participate}

All animal experimental procedures were carried out following the Guide for the Care and Use of Laboratory Animals of Huai'an First People's Hospital, Nanjing Medical University (Nanjing, China) and before the animal experiments were performed, the procedures were approved by the Research Ethics Committee of Huai'an First People's Hospital, Nanjing Medical University (Nanjing, China).

\section{Consent for publication}

Not applicable.

\section{Competing interests}

The authors state that they have no competing interests.

\section{References}

1. Eisemann N, Waldmann A, Geller AC, Weinstock MA, Volkmer B, Greinert R, Breitbart EW and Katalinic A: Non-melanoma skin cancer incidence and impact of skin cancer screening on incidence. J Invest Dermatol 134: 43-50, 2014.

2. Katalinic A, Eisemann N and Waldmann A: Skin cancer screening in Germany. Dtsch Arztebl Int 112: 629-634, 2015.

3. Fusi C, Materazzi S, Minocci D, Maio V, Oranges T, Massi D and Nassini R: Transient receptor potential vanilloid 4 (TRPV4) is downregulated in keratinocytes in human non-melanoma skin cancer. J Invest Dermatol 134: 2408-2417, 2014.

4. Brantsch KD, Meisner C, Schönfisch B, Trilling B, WehnerCaroli J, Röcken $\mathrm{M}$ and Breuninger $\mathrm{H}$ : Analysis of risk factors determining prognosis of cutaneous squamous-cell carcinoma: a prospective study. Lancet Oncol 9: 713-720, 2008.

5. Surdu S, Fitzgerald EF, Bloom MS, Boscoe FP, Carpenter DO, Haase RF, Gurzau E, Rudnai P, Koppova K, Vahter M, et al: Polymorphisms in DNA repair genes XRCC1 and XRCC3, occupational exposure to arsenic and sunlight, and the risk of non-melanoma skin cancer in a European case-control study. Environ Res 134: 382-389, 2014.

6. Ju Q and Zouboulis CC: Endocrine-disrupting chemicals and skin manifestations. Rev Endocr Metab Disord 17: 449-457, 2016.

7. Goldenberg A, Ortiz A, Kim SS and Jiang SB: Squamous cell carcinoma with aggressive subclinical extension: 5-year retrospective review of diagnostic predictors. J Am Acad Dermatol 73: 120-126, 2015.

8. Goldstein J, Roth E, Roberts N, Zwick R, Lin S, Fletcher S, Tadeu A, Wu C, Beck A, Zeiss C, et al: Loss of endogenous Nfatcl reduces the rate of DMBA/TPA-induced skin tumorigenesis. Mol Biol Cell 26: 3606-3614, 2015.

9. Bai Y, Edamatsu H, Maeda S, Saito H, Suzuki N, Satoh T and Kataoka T: Crucial role of phospholipase Cepsilon in chemical carcinogen-induced skin tumor development. Cancer Res 64: 8808-8810, 2004.

10. Wang Z, Pedersen E, Basse A, Lefever T, Peyrollier K, Kapoor S, Mei Q, Karlsson R, Chrostek-Grashoff A and Brakebusch C: Rac1 is crucial for Ras-dependent skin tumor formation by controlling Pak1-Mek-Erk hyperactivation and hyperproliferation in vivo. Oncogene 29: 3362-3373, 2010.

11. Drexler SK, Bonsignore L, Masin M, Tardivel A, Jackstadt R, Hermeking H, Schneider P, Gross O, Tschopp J and Yazdi AS: Tissue-specific opposing functions of the inflammasome adaptor ASC in the regulation of epithelial skin carcinogenesis. Proc Natl Acad Sci USA 109: 18384-18389, 2012.

12. Kang NJ, Jung SK, Lee KW and Lee HJ: Myricetin is a potent chemopreventive phytochemical in skin carcinogenesis. Ann NY Acad Sci 1229: 124-132, 2011.

13. Manoharan S and Selvan MV: Chemopreventive potential of geraniol in 7,12-dimethylbenz(a) anthracene (DMBA) induced skin carcinogenesis in Swiss albino mice. J Environ Biol 33: 255-260, 2012.

14. Qian EW, Ge DT and Kong SK: Salidroside protects human erythrocytes against hydrogen peroxide-induced apoptosis. J Nat Prod 75: 531-537, 2012.

15. Wang S, He H, Chen L, Zhang W, Zhang X and Chen J: Protective effects of salidroside in the MPTP/MPP(+)-induced model of Parkinson's disease through ROS-NO-related mitochondrion pathway. Mol Neurobiol 51: 718-728, 2015.

16. Zhu L, Chen T, Chang X, Zhou R, Luo F, Liu J, Zhang K, Wang Y, Yang Y, Long H, et al: Salidroside ameliorates arthritis-induced brain cognition deficits by regulating Rho/ROCK/NF- $\kappa \mathrm{B}$ pathway. Neuropharmacology 103: 134-142, 2016.

17. Zhang S, Chen X, Yang Y, Zhou X, Liu J and Ding F: Neuroprotection against cobalt chloride-induced cell apoptosis of primary cultured cortical neurons by salidroside. Mol Cell Biochem 354: 161-170, 2011.

18. Li X, Ye X, Li X, Sun X, Liang Q, Tao L, Kang X and Chen J: Salidroside protects against MPP(+)-induced apoptosis in PC12 cells by inhibiting the NO pathway. Brain Res 1382: 9-18, 2011.

19. Yang DW, Kang OH, Lee YS, Han SH, Lee SW, Cha SW, Seo YS, Mun SH, Gong R, Shin DW, et al: Anti-inflammatory effect of salidroside on phorbol-12-myristate-13-acetate plus A23187mediated inflammation in HMC-1 cells. Int J Mol Med 38: 1864-1870, 2016.

20. Shan Y, Wei Z, Tao L, Wang S, Zhang F, Shen C, Wu H, Liu Z, Zhu P, Wang A, et al: Prophylaxis of diallyl disulfide on skin carcinogenic model via p21-dependent Nrf2 stabilization. Sci Rep 6: 35676, 2016. 
21. Saw CL, Huang MT, Liu Y, Khor TO, Conney AH and Kong AN: Impact of Nrf2 on UVB-induced skin inflammation/photoprotection and photoprotective effect of sulforaphane. Mol Carcinog 50: 479-486, 2011.

22. Kim EJ, Park H, Kim J and Park JH: 3,3'-diindolylmethane suppresses 12-O-tetradecanoylphorbol-13-acetate-induced inflammation and tumor promotion in mouse skin via the downregulation of inflammatory mediators. Mol Carcinog 49: 672-683, 2010.

23. Mahdavian Delavary B, van der Veer WM, van Egmond M, Niessen FB and Beelen RH: Macrophages in skin injury and repair. Immunobiology 216: 753-762, 2011.

24. Sellami H, Said-Sadier N, Znazen A, Gdoura R, Ojcius DM and Hammami A: Chlamydia trachomatis infection increases the expression of inflammatory tumorigenic cytokines and chemokines as well as components of the Toll-like receptor and NF- $\kappa \mathrm{B}$ pathways in human prostate epithelial cells. Mol Cell Probes 28: 147-154, 2014

25. Xu X, Yang H, Wang X and Tu Y: The significance of nuclear factor-kappa B signaling pathway in glioma: A review. Cancer Transl Med 3: 181-184, 2017.

26. Liu Y, Liu Y, Xu D and Li J: Latanoprost-induced cytokine and chemokine release rrom human Tenon's capsule fibroblasts: Role of MAPK and NF- $\kappa$ B signaling pathways. J Glaucoma 24 635-641, 2015.

27. Wang HC, Yang JH, Hsieh SC and Sheen LY: Allyl sulfides inhibit cell growth of skin cancer cells through induction of DNA damage mediated G2/M arrest and apoptosis. J Agric Food Chem 58: 7096-7103, 2010

28. Wang T, Yang S, Mei LA, Parmar CK, Gillespie JW, Praveen KP, Petrenko VA and Torchilin VP: Paclitaxel-loaded PEG-PE-based micellar nanopreparations targeted with tumor-specific landscape phage fusion protein enhance apoptosis and efficiently reduce tumors. Mol Cancer Ther 13: 2864-2875, 2014.

29. Zhao Y, Guo Q, Chen J, Hu J, Wang S and Sun Y: Role of long non-coding RNA HULC in cell proliferation, apoptosis and tumor metastasis of gastric cancer: A clinical and in vitro investigation. Oncol Rep 31: 358-364, 2014.

30. Claerhout S, Verschooten L, Van Kelst S, De Vos R, Proby C, Agostinis P and Garmyn M: Concomitant inhibition of AKT and autophagy is required for efficient cisplatin-induced apoptosis of metastatic skin carcinoma. Int J Cancer 127: 2790-2803, 2010

31. Strozyk E and Kulms D: The role of AKT/mTOR pathway in stress response to UV-irradiation: Implication in skin carcinogenesis by regulation of apoptosis, autophagy and senescence. Int J Mol Sci 14: 15260-15285, 2013.

32. Li D, Fu Y, Zhang W, Su G, Liu B, Guo M, Li F, Liang D, Liu Z, Zhang $\mathrm{X}$, et al: Salidroside attenuates inflammatory responses by suppressing nuclear factor- $\kappa \mathrm{B}$ and mitogen activated protein kinases activation in lipopolysaccharide-induced mastitis in mice. Inflamm Res 62: 9-15, 2013.

33. Zhu L, Wei T, Gao J, Chang X, He H, Luo F, Zhou R, Ma C, Liu Y and Yan T: The cardioprotective effect of salidroside against myocardial ischemia reperfusion injury in rats by inhibiting apoptosis and inflammation. Apoptosis 20: 1433-1443, 2015.

34. Fu W, McCormick T, Qi X, Luo L, Zhou L, Li X, Wang BC, Gibbons HE, Abdul-Karim FW and Gorodeski GI: Activation of P2X(7)-mediated apoptosis inhibits DMBA/TPA-induced formation of skin papillomas and cancer in mice. BMC Cancer 9 : $114,2009$.

35. Zhang XR, Fu XJ, Zhu DS, Zhang CZ, Hou S, Li M and Yang XH: Salidroside-regulated lipid metabolism with down-regulation of miR-370 in type 2 diabetic mice. Eur J Pharmacol 779: 46-52, 2016

36. Xu MX, Zhao L, Deng C, Yang L, Wang Y, Guo T, Li L, Lin J and Zhang L: Curcumin suppresses proliferation and induces apoptosis of human hepatocellular carcinoma cells via the wnt signaling pathway. Int J Oncol 43: 1951-1959, 2013.

37. Wang X, Simpson ER and Brown KA: p53: protection against tumor growth beyond effects on cell cycle and apoptosis. Cancer Res 75: 5001-5007, 2015.

38. Madan V, Lear JT and Szeimies RM: Non-melanoma skin cancer. Lancet 375: 673-685, 2010.

39. Saw CLL, Yang AY, Huang MT, Liu Y, Lee JH, Khor TO, Su ZY, Shu L, Lu Y, Conney AH, et al: Nrf2 null enhances UVB-induced skin inflammation and extracellular matrix damages. Cell Biosci 4: 39, 2014

40. Chinembiri TN, du Plessis LH, Gerber M, Hamman JH and du Plessis J: Review of natural compounds for potential skin cancer treatment. Molecules 19: 11679-11721, 2014.

41. Simões MCF, Sousa JJS and Pais AA: Skin cancer and new treatment perspectives: A review. Cancer Lett 357: 8-42, 2015.
42. Ma C, Hu L, Tao G, Lv W and Wang H: An UPLC-MS-based metabolomics investigation on the anti-fatigue effect of salidroside in mice. J Pharm Biomed Anal 105: 84-90, 2015.

43. Zhong X, Lin R, Li Z, Mao J and Chen L: Effects of Salidroside on cobalt chloride-induced hypoxia damage and mTOR signaling repression in PC12 cells. Biol Pharm Bull 37: 1199-1206, 2014.

44. Tsimikas S, Duff GW, Berger PB, Rogus J, Huttner K, Clopton P, Brilakis E, Kornman KS and Witztum JL: Pro-inflammatory interleukin-1 genotypes potentiate the risk of coronary artery disease and cardiovascular events mediated by oxidized phospholipids and lipoprotein(a). J Am Coll Cardiol 63: 1724-1734, 2014.

45. Lofrumento DD, Nicolardi G, Cianciulli A, De Nuccio F, La Pesa V, Carofiglio V, Dragone T, Calvello R and Panaro MA: Neuroprotective effects of resveratrol in an MPTP mouse model of Parkinson's-like disease: Possible role of SOCS-1 in reducing pro-inflammatory responses. Innate Immun 20: 249-260, 2014.

46. Kim BH, Choi MS, Lee HG, Lee SH, Noh KH, Kwon S, Jeong AJ, Lee H, Yi EH, Park JY, et al: Photoprotective potential of penta$\mathrm{O}$-galloyl- $\beta$-Dglucose by targeting NF- $\mathrm{KB}$ and MAPK signaling in UVB radiation-induced human dermal fibroblasts and mouse skin. Mol Cells 38: 982-990, 2015.

47. Yuan L, Wu Y, Ren X, Liu Q, Wang J and Liu X: Isoorientin attenuates lipopolysaccharide-induced pro-inflammatory responses through down-regulation of ROS-related MAPK/NF- $\kappa \mathrm{B}$ signaling pathway in BV-2 microglia. Mol Cell Biochem 386: $153-165,2014$.

48. Lin TH, Yao Z, Sato T, Keeney M, Li C, Pajarinen J, Yang F, Egashira K and Goodman SB: Suppression of wear-particleinduced pro-inflammatory cytokine and chemokine production in macrophages via NF- $\mathrm{B}$ decoy oligodeoxynucleotide: $\mathrm{A}$ preliminary report. Acta Biomater 10: 3747-3755, 2014.

49. Choi H, Nguyen HN and Lamb FS: Inhibition of endocytosis exacerbates TNF- $\alpha$-induced endothelial dysfunction via enhanced JNK and p38 activation. Am J Physiol Heart Circ Physiol 306: H1154-H1163, 2014.

50. Schett G, Dayer JM and Manger B: Interleukin-1 function and role in rheumatic disease. Nat Rev Rheumatol 12: 14-24, 2016.

51. Wu L, Zhou Y, Zhou Z, Liu Y, Bai Y, Xing X and Wang X: Nicotine induces the production of IL-1 $\beta$ and IL-8 via the $\alpha$ 7 $\mathrm{nAChR} / \mathrm{NF}-\kappa \mathrm{B}$ pathway in human periodontal ligament cells: An in vitro study. Cell Physiol Biochem 34: 423-431, 2014.

52. Wang Q, He Y, Shen Y, Zhang Q, Chen D, Zuo C, Qin J, Wang H, Wang J and Yu Y: Vitamin D inhibits COX-2 expression and inflammatory response by targeting thioesterase superfamily member 4. J Biol Chem 289: 11681-11694, 2014.

53. Kumar D, Tewari-Singh N, Agarwal C, Jain AK, Inturi S, Kant R, White CW and Agarwal R: Nitrogen mustard exposure of murine skin induces DNA damage, oxidative stress and activation of MAPK/Akt-AP1 pathway leading to induction of inflammatory and proteolytic mediators. Toxicol Lett 235: 161-171, 2015.

54. Marvel D and Gabrilovich DI: Myeloid-derived suppressor cells in the tumor microenvironment: Expect the unexpected. J Clin Invest 125: 3356-3364, 2015.

55. Song J, Feng L, Zhong R, Xia Z, Zhang L, Cui L, Yan H, Jia X and Zhang Z: Icariside II inhibits the EMT of NSCLC cells in inflammatory microenvironment via down-regulation of $\mathrm{Akt} / \mathrm{NF}-\kappa \mathrm{B}$ signaling pathway. Mol Carcinog 56: 36-48, 2017.

56. Nie FQ, Sun M, Yang JS, Xie M, Xu TP, Xia R, Liu YW, Liu XH, Zhang EB, Lu KH, et al: Long noncoding RNA ANRIL promotes non-small cell lung cancer cell proliferation and inhibits apoptosis by silencing KLF2 and P21 expression. Mol Cancer Ther 14: 268-277, 2015.

57. Dai H, Meng XW and Kaufmann SH: BCL2 family, mitochondrial apoptosis, and beyond. Cancer Transl Med 2: 7-20, 2016.

58. White MJ, McArthur K, Metcalf D, Lane RM, Cambier JC, Herold MJ, van Delft MF, Bedoui S, Lessene G, Ritchie ME, et al: Apoptotic caspases suppress mtDNA-induced STINGmediated type I IFN production. Cell 159: 1549-1562, 2014

59. Samarghandian S, Azimi Nezhad M, Mohammadi G. Role of caspases, Bax and Bcl-2 in chrysin-induced apoptosis in the A549 human lung adenocarcinoma epithelial cells. Anticancer Agents Med Chem 14: 901-909, 2014.

60. Jiang $\mathrm{X}$, Jiang $\mathrm{H}$, Shen $\mathrm{Z}$ and Wang $\mathrm{X}$ : Activation of mitochondrial protease OMA1 by Bax and Bak promotes cytochrome c release during apoptosis. Proc Natl Acad Sci USA 111: 14782-14787, 2014.

61. Seth R, Corniola RS, Gower-Winter SD, Morgan TJ Jr, Bishop B and Levenson CW: Zinc deficiency induces apoptosis via mitochondrial p53- and caspase-dependent pathways in human neuronal precursor cells. J Trace Elem Med Biol 30: 59-65, 2015. 
62. Al-Fatlawi AA, Al-Fatlawi AA, Irshad M,Zafaryab M, Rizvi MM and Ahmad A: Rice bran phytic acid induced apoptosis through regulation of $\mathrm{Bcl}-2 / \mathrm{Bax}$ and 553 genes in HepG2 human hepatocellular carcinoma cells. Asian Pac J Cancer Prev 15: 3731-3736, 2014.

63. Gu JJ, Zhang Q, Mavis C, Czuczman MS and HernandezIlizaliturri FJ: Metformin induces p53-dependent mitochondrial stress in therapy-sensitive and-resistant lymphoma pre-clinical model and primary patients sample with B-cell non-Hodgkin lymphoma (NHL). Blood 126: 4008-4008, 2015.

64. Song H, Wei M, Liu W, Shen S, Li J and Wang L: Cisplatin induced apoptosis of ovarian cancer A2780s cells by activation of ERK/p53/PUMA signals. Histol Histopathol: Mar 13, 2017 (Epub ahead of print). doi: 10.14670/HH-11-889.

65. Renault TT, Floros KV, Elkholi R, Corrigan KA, Kushnareva Y, Wieder SY, Lindtner C, Serasinghe MN, Asciolla JJ, Buettner C, et al: Mitochondrial shape governs BAX-induced membrane permeabilization and apoptosis. Mol Cell 57: 69-82, 2015.

66. Singh N, Sarkar J, Sashidhara KV, Ali S and Sinha S: Antitumour activity of a novel coumarin-chalcone hybrid is mediated through intrinsic apoptotic pathway by inducing PUMA and altering Bax/Bcl-2 ratio. Apoptosis 19: 1017-1028, 2014.
67. Shamanna RA, Hoque M, Pe'ery T and Mathews MB: Induction of p53, p21 and apoptosis by silencing the NF90/NF45 complex in human papilloma virus-transformed cervical carcinoma cells. Oncogene 32: 5176-5185, 2013.

68. Dong X, Zhang X, Li D, Li B, Wang J, Meng S, Luo W and Zhang W: Protective effect of salidroside against high altitude hypoxia-induced brain injury in rats. Xi Bao Yu Fen Zi Mian Yi Xue Za Zhi 31: 1327-1331, 2015 (In Chinese).

69. Teng L, Gao JF, Zhou L, Xian QY, Li JK and Yang SJ: Influence of salidroside on expression level of endothelin-1 and its receptors under hypoxic conditions in chicken embryonic pulmonary artery smooth muscle cells. Pak Vet J 36: 214-218, 2016.

70. Fan XJ, Wang Y, Wang L and Zhu M: Salidroside induces apoptosis and autophagy in human colorectal cancer cells through inhibition of PI3K/Akt/mTOR pathway. Oncol Rep 36: 3559-3567, 2016.

cc)(1) (9) This work is licensed under a Creative Commons

EY NO NO Attribution-NonCommercial-NoDerivatives 4.0 International (CC BY-NC-ND 4.0) License. 